\author{
RESEARCH ARTICLE \\ 10.1029/2019JC015811 \\ Key Points: \\ - A semianalytical algorithm was \\ developed for removing the \\ intermission bias in $R_{\mathrm{rs}}$ data \\ - The algorithm can produce $<3 \%$ \\ intermission bias for IOPs retrieval \\ with high quality $R_{\mathrm{rs}}$ data \\ - The intermission difference can \\ affect the trend analysis results in \\ the open ocean
}

Correspondence to:

D. Pan,

pandelu@sio.org.cn

Citation:

Chen, J., He, X., Xing, X., Xing, Q., Liu, Z., \& Pan, D. (2020). An inherent optical properties data processing system for achieving consistent ocean color products from different ocean color satellites. Journal of Geophysical Research: Oceans, 125, e2019JC015811. https://doi.org/10.1029/2019JC015811

Received 10 NOV 2019 Accepted 12 DEC 2019 Accepted article online 19 DEC 2019

(C)2019. American Geophysical Union. All Rights Reserved.

\section{An Inherent Optical Properties Data Processing System for Achieving Consistent Ocean Color Products From Different Ocean Color Satellites}

\author{
Jun Chen ${ }^{1,2}$, Xianqiang $\mathrm{He}^{2}$, Xiaogang Xing ${ }^{2}$, Qianguo Xing ${ }^{3}$, Zhongli Liu', and Delu Pan ${ }^{2}$ \\ ${ }^{1}$ School of Human Settlements and Civil Engineering, Xi'an Jiaotong University, Xi'an, China, ${ }^{2}$ State Key Laboratory of \\ Satellite Ocean Environment Dynamics, Second Institute of Oceanography, Ministry of Natural Resources, Hangzhou, \\ China, ${ }^{3}$ Yantai Institute of Coastal Zone Research, Chinese Academy of Sciences, Yantai, China
}

Abstract We used field measurements and multimission satellite data to evaluate how well an inherent optical properties (IOPs) data processing system performed at correcting the residual error of the atmospheric correction in satellite remote sensing reflectance $\left(R_{\mathrm{rs}}\right)$ and how well the system simultaneously minimized intermission biases between different remote sensing systems. We developed the IOPs data processing system as a semianalytical algorithm called IDAS. Our results show that IDAS generates accurate and consistent IOPs products from two ocean color missions: Sea-viewing Wide Field-of-View Sensor (SeaWiFS) and Moderate Resolution Imaging Spectroradiometer Aqua (MODISA). Specifically, with "high-quality" SeaWiFS and MODISA $R_{\mathrm{rs}}$ data, IDAS provided temporally consistent IOPs products for the oligotrophic open ocean resulting in an annual mean intermission difference of less than $3 \%$, which is significantly lower than what a quasi-analytical algorithm (QAA) provided. We used IDAS to generate a long time series of $b_{\mathrm{b}}$ (555) from the Northwest Atlantic Subtropical Gyre using SeaWiFS (1998 to 2002) and MODISA (2003 to 2017) images. Our results show that the IDAS-derived annual $b_{\mathrm{b}}(555)$ decreased monotonically by $2.81 \%$ per decade from 1998 to 2017. Comparing the IDAS-generated annual trend for $b_{\mathrm{b}}(555)$ to the same data processed with the QAA algorithm, we found that the QAA results differed because of impacts of the residual errors of the atmospheric correction and intermission biases. The differences in the annual trends existed despite the same temporal changing patterns of in situ particulate organic carbon existing in the Sargasso Sea and in the satellite chlorophyll-a concentration in the Northwest Atlantic Subtropical Gyre.

\section{Introduction}

Using ocean color data to understand oceanic primary production and climate change on a global scale is a widespread approach. The National Aeronautics and Space Administration (NASA) oversees a continuous mission for gathering global ocean color observations. NASA launched the SeaStar satellite equipped with the Sea-viewing Wide Field-of-View Sensor (SeaWiFS). NASA also launched the Earth Observing System equipped with the Moderate Resolution Imaging Spectroradiometer onboard Aqua (MODISA). Following the success of the first ocean color mission, Coastal Zone Color Scanner (Aiken et al., 1995; Gordon et al., 1980), NASA designed these recent missions to have less than $5 \%$ uncertainty in water-leaving radiances for blue wavelengths in blue water (Ahmad et al., 2010; Gordon \& Wang, 1994) and less than 35\% uncertainty in chlorophyll-a concentration estimates in the open ocean (Carder et al., 2004; Wang \& Son, 2016). These well-calibrated ocean color data improve our knowledge of regional marine ecological disasters and global biological cycles, which include when spring blooms begin (Mahadevan et al., 2012; Siegel et al., 2002; Tin et al., 2016), heat fluxes in the upper ocean (Ballabrera-Poy et al., 2007; Lewis et al., 1990; Strutton \& Chavez, 2004; Zhang, 2016; Zhang et al., 2015), mixed layer depth anomalies caused by changing biomass (Cotroneo et al., 2016), carbon cycles (Roy et al., 2017), and other biochemical processes (Ford \& Barciela, 2017).

Separating the signature of basin-scale ecological oscillations from potential climate change in the ocean requires a long time series of consistent satellite observations. However, because of the typical short lifetime of ocean color satellites, it is common to combine several successive missions into a single data set to increase observation time scales beyond the limited lifetime of a single mission, for example, making the shift from a single satellite centric datum to a variable-centric one (Mélin et al., 2017). It is commonly assumed that 
single-mission ocean color data are free of spurious temporal artifacts so that these data can be used as the benchmark of a time series (Lee et al., 2010; Siegel et al., 2002). However, for this assumption to be true, multimission ocean color data should reproduce the trends within each single-mission series when calculating the trend over the same period despite any intermission differences (Gao et al., 2018; Gregg \& Casey, 2010; Mélin et al., 2017). The confidence in results acquired from applying ocean color data at climatic time scales lies greatly in this intermission consistency.

Chlorophyll-a concentration is an essential climate variable of the global climate observing system (Bojinski et al., 2014). Thus, it is not unusual that many scholars have focused on improving the intermission consistency of chlorophyll-a concentration (Ballabrera-Poy et al., 2003; Gregg \& Conkright, 2001; IOCCG, 2007; Kwiatkowska \& Fargion, 2003; Pottier et al., 2006; Zhang et al., 2006). For instance, Gregg and Casey (2010) stated that the intermission difference in chlorophyll-a concentration between SeaWiFS and MODISA exceeded the maximum interannual amplitude variation in the global and major oceanographic basins. Later, Gregg and Casey developed an empirical satellite and in situ data algorithm to minimize these inconsistencies. Mélin (2016) showed that the $\pm 5 \%$ intermission difference could lead to a trend that was significantly different from the trend derived from a corrected reference series. However, these intermission inconsistencies could be improved using a bias correction scheme that Mélin et al. (2017) proposed.

In addition to chlorophyll-a concentration, we need to reliably obtain intermission consistency for other optical and biogeochemical products, such as inherent optical properties (IOPs) (Behrenfeld et al., 2009; Boyce et al., 2010; Son \& Wang, 2015). IOPs control the natural changes of ocean color, which is another essential climate variable (Bojinski et al., 2014).

To retrieve consistent IOPs from multimission ocean color data (Garver \& Siegel, 1997; IOCCG, 2006; Kahru et al., 2015; Lee et al., 2002; Werdell et al., 2013), we must remove the difference in remote sensing reflectance $\left(R_{\mathrm{rs}}\right)$ products between missions. Maritorena and Siegel (2005) assumed that the normalized water-leaving radiances observed from different satellites had similar uncertainty levels so that optical data from different sensors could be combined. In theory, the bio-optical algorithm that Garver and Siegel (1997) developed could be used to combine the optical data from different sensors, but the effect of an intermission difference in $R_{\mathrm{rs}}$ would still propagate through the algorithm to the retrieved IOPs. Practically, due to differences in sensitivities, signal-to-noise ratios, calibration and degradation histories, observation times, data processing systems, observation geometries, weather conditions, and so on (Ahmad et al., 2010; Gordon \& Voss, 1999; Gordon \& Wang, 1994; Yuan et al., 2019), the radiance products observed from various satellites differ significantly, even for the same nominal band (Mélin et al., 2016).

To mitigate the effects of intermission differences, Kahru et al. (2015) suggested applying an empirical linear adjustment to remove the difference between missions when retrieving IOPs for the California current. As a result of their adjustment, their merged time series had a more dominant annual cycle than the original time series. In a different attempt at correcting for intermission differences, the CCI (2016) expressed the target satellite $R_{\mathrm{rs}}$ at SeaWiFS wavebands through a band-shifting scheme. Then CCI applied a bias correction to a SeaWiFS reflectance data set. But despite these early attempts at removing intermission differences, there are still many sources of intermission difference in $R_{\mathrm{rs}}$ data that cannot be effectively removed using a simple adjustment or correction so an accurate algorithm is needed.

Due to differences in instrument spectral characteristics, it is difficult to find two satellites with the same $R_{\mathrm{rs}}$. The residual error is the error that remains in satellite $R_{\mathrm{rs}}$ after processing with an imperfect procedure, including atmospheric correction. The intermission bias is the difference between the $R_{\mathrm{rs}}$ from two different satellites due to the discrepancies in the wavelength systems and overpass times. Therefore, the intermission difference $\left(\triangle R_{\mathrm{rs}, \mathrm{d}}\right)$ is the sum of residual error and the intermission bias. The residual error in satellite $R_{\mathrm{rs}}$ is a data uncertainty, which is mainly due to imperfect data processing and includes instrument noise, irradiance calibration, and atmospheric correction (Ahmad et al., 2010; Gordon \& Wang, 1994; Hu et al., 2013).

NASA's default data processing procedure for atmospheric correction uses the black pixel assumption at near-infrared bands (Gordon \& Voss, 1999). In NASA's procedure, first the aerosol type and reflectance at near-infrared regions are determined with the black pixel assumption. Then the near-infrared regions are extrapolated to visible bands with a lookup table (Gordon \& Wang, 1994). When the aerosol reflectance at visible bands is known, we obtain the satellite $R_{\mathrm{rs}}$ by subtracting the aerosol contribution from the Rayleigh-corrected total satellite signal. For well-calibrated satellite instruments such as MODISA and 
SeaWiFS, the residual error is more like an additive uncertainty not a multiplying uncertainty, which is consistent with what Hu et al. (2013) proposed. The intermission bias is not an uncertainty; it is the bias between two true satellite $R_{\mathrm{rs}}$. Therefore, it might be acceptable to deem the intermission bias to be an additive item in an intermission difference analysis and simultaneously differentiate the two uncertainty concepts between residual error and intermission bias. In addition to affecting the residual errors, the intermission bias can also affect the intermission consistency of IOPs products derived from multiple missions.

Chen et al. (2016) developed a semianalytical IOPs data processing system for retrieving IOPs from satellite $R_{\mathrm{rs}}$. Their algorithm simultaneously corrected residual errors in satellite $R_{\mathrm{rs}}\left(\triangle R_{\mathrm{rs}, \mathrm{r}}\right)$ with a residual error correction (REC) algorithm. The results showed that the residual errors decreased the smoothness of the time series of IOPs for the open ocean, which could increase the intermission difference. The semianalytical processing algorithm (IDAS) that Chen et al. developed retrieves the spatially and temporally consistent IOPs products from a single ocean color satellite in the open oceans (Chen et al., 2016). However, we still do not know whether the IDAS algorithm can provide an improved intermission consistency of $R_{\mathrm{rs}}$ and IOPs products. We especially do not know to what extent the physical mechanism of the IDAS algorithm improves the intermission consistency.

In this study, we introduce the IDAS algorithm and use SeaWiFS and MODISA data as processing examples after first describing these data sets. We show how the physical mechanism of the IDAS algorithm compensates for intermission bias in the solution for the residual error in the closed equations of the REC algorithm. Furthermore, we present the significant improvements that the IDAS algorithm produced in intermission consistency for retrieving IOPs from "ocean deserts" because the oligotrophic oceans are more sensitive to intermission differences than other types of seas (Mélin, 2016). Lastly, using the backscattering coefficient at $555 \mathrm{~nm}$ in the Northwest Atlantic Subtropical Ocean as an example, we show how important multimission consistency of $R_{\mathrm{rs}}$ observations is to temporal trend analysis.

\section{Data and Methods}

\subsection{Testing and Assessing the Data}

We used in situ measurements and satellite images to assess how well IDAS performed in producing consistent products from multiple missions over the open ocean. We used three different kinds of data sets to assess IDAS:

1. Simple synthetic data to test how well IDAS reduces intermission bias in REC

2. Sample point data to see how well IDAS retrieves $a(443)$

3. Satellite data to compare the performance of IDAS to the performance of two other similar algorithms

\subsubsection{In Situ Measurements}

Our in situ data set (see Table 2) was the NASA bio-optical marine algorithm data set (NOMAD) (Werdell \& Bailey, 2002). The NASA Ocean Biology Processing Group compiled these data from global field measurements archived in the SeaWiFS Bio-optical Archive and Storage System. This data set includes measured $R_{\mathrm{rs}}$ values at the SeaWiFS wavelengths and IOPs data (Werdell \& Bailey, 2002). The NOMAD data were filtered with $R_{\mathrm{rs}}(\lambda)>0$ at blue and green SeaWiFS wavelengths. In addition, we had in situ particulate organic carbon (POC) concentrations at the ocean surface $(<5 \mathrm{~m})$ from the Bermuda time series site (Gundersen et al., 2001). We used the POC to validate the annual trends of the backscattering coefficient that we produced with IDAS and a quasi-analytical algorithm (QAA). All the data were measured following rigorous and community-defined protocols for deploying and collecting data (Mueller et al., 2003) with in situ radiometric measurement uncertainties on the order of 3\% to 5\% under ideal conditions (Bailey \& Werdell, 2006; Hooker et al., 2001).

\subsubsection{Satellite Data}

We used the SeaWiFS Level-2 Global Area Coverage (GAC) image collected from over the Sargasso Sea on 20 February 1998 to assess how $\triangle R_{\mathrm{rs}, \mathrm{r}}$ for a single mission influenced the IDAS and QAA algorithms when retrieving IOPs. In addition, we used the coincident MODISA Level-2 Local Area Coverage (LAC) images over the North Atlantic Gyre $\left(17^{\circ}\right.$ to $27^{\circ} \mathrm{N}, 54^{\circ}$ to $\left.60^{\circ} \mathrm{W}\right)$ from 12 October 2006 to evaluate how well the IDAS algorithm reduced impacts of intermission difference in $R_{\mathrm{rs}}$ data when retrieving IOPs. We obtained the SeaWiFS Level-2 GAC data and MODISA Level-2 LAC data from the NASA/Goddard Space Flight Center in March 2018. 
To minimize the interface of the intermission bias between MODISA and SeaWiFS caused by spectral characteristics on IOPs retrievals, we used the green MODISA band at $555 \mathrm{~nm}$ even though the green MODISA band at $555 \mathrm{~nm}$ was not originally designed for ocean color applications. We could not use the green MODISA band designed for ocean color applications (the band at $547 \mathrm{~nm}$ ) because it was about $8 \mathrm{~nm}$ shorter than the green SeaWiFS band at $555 \mathrm{~nm}$. We used the satellite data for evaluating the algorithms so which satellite band was better was not important. Furthermore, our practical data processing results showed that the green MODISA band at $555 \mathrm{~nm}$ could be used for ocean color study after correcting for the residual error, even though the signal-to-noise ratio was very low. Thus, for our study, the MODISA images represented $R_{\mathrm{rs}}$ data at $412,443,488,555$, and $667 \mathrm{~nm}$, and the SeaWiFS images referred to $R_{\mathrm{rs}}$ data at 412, 443, 490, 555, and $670 \mathrm{~nm}$.

The 1987 daily SeaWiFS Level-2 GAC images were from 1998 to 2003 and the 12,823 daily MODISA Level-2 LAC images were from 2004 to 2017. All the images covered the oligotrophic North Atlantic Gyre ( $17^{\circ}$ to $34^{\circ} \mathrm{N}, 50^{\circ}$ to $60^{\circ} \mathrm{W}$ ). In addition, we obtained 172 SeaWiFS Level-2 GAC images and 904 MODISA Level-2 LAC images over the oligotrophic South Pacific Gyre $\left(34^{\circ}\right.$ to $36^{\circ} \mathrm{S}, 114^{\circ}$ to $\left.116^{\circ} \mathrm{W}\right)$ from 2009 to see how well IDAS achieved consistent products from multiple missions over an oligotrophic ocean compared to the QAA algorithm. The spatial resolution of the SeaWiFS Level-2 GAC images was about $4 \mathrm{~km}$, and the spatial resolution of the MODISA Level-2 LAC images was about $1 \mathrm{~km}$.

In March 2018, the NASA/Goddard Space Flight Center provided us with 365 daily SeaWiFS and MODISA Level-3 images from 2006 with 9-km resolution over the oligotrophic Northwest Atlantic Subtropical Ocean $\left(20^{\circ}\right.$ to $30^{\circ} \mathrm{N}, 50^{\circ}$ to $\left.60^{\circ} \mathrm{W}\right)$. We used these images to calculate gain factors between the satellites to understand the natural intermission difference between MODISA and SeaWiFS $R_{\mathrm{rs}}$ data for the global ocean. The Level-3 images were filtered with high quality exclusion criteria that included an 12_flags mask and accurate geometric correction.

It is hard to accurately correct geometry for the open ocean in SeaWiFS and MODISA images due to the lack of notable corresponding image points. The lack of corresponding image points means that analyzing the images pixel-by-pixel would be restricted so that, inevitably, there would be some differences in spatial resolution and geometric deformation between the SeaWiFS and MODISA Level-2 images. To circumvent this problem, we analyzed the intermission consistency temporally with image statistics based on a small homogeneous area common to image pairs instead of comparing images pixel by pixel. We used the mean value of a square region in a daily image to compare patterns as they changed in time for each satellite. However, there might not have been enough valid pixels for a temporal analysis due to cloud coverage so the size of the square region would be too small. Conversely, the temporal changing pattern might have been disturbed by a spatially changing characteristic if the size of the square region were too large. Therefore, we used a practical data processing experiment to empirically define the size of the square region as $2^{\circ} \times 2^{\circ}$ for the open ocean. Defining a standard size for the square region allowed us to reasonably evaluate how well IDAS removed the intermission difference. In addition, we used original and corrected pixel-based histograms to show the changes in the intermission consistency before and after correcting for the intermission difference. Using the original and corrected histograms minimized effects of the small difference associated with the spatial resolution and effects of geometric deformation on the shape of the histograms.

\subsection{General Description of IDAS}

Unlike the IOPs retrieval algorithm for a single-mission satellite, IDAS obtains consistent IOPs products from multimission data in the open ocean. IDAS is a step-wise procedure, and we explain each step that we performed here. (Figure 1). First, we estimated the $\triangle R_{\mathrm{rs}, \mathrm{r}}$ at $670 \mathrm{~nm}$ using a REC algorithm (Chen et al., 2016), then we extended the derivation to other wavelengths with an empirical spectral relationship determined using $\mathrm{Hu}$ et al.'s (2013) algorithm. Next, we removed the residual errors in satellite $R_{\mathrm{rs}}$ using REC-corrected $\triangle R_{\mathrm{rs}, \mathrm{r}}$, after which we derived the absorption and backscattering coefficients from the error-corrected $R_{\mathrm{rs}}$ using the neural network-based quasi-analytical algorithm (NQAA) (Chen et al., 2016).

Using SeaWiFS and MODISA as examples, we detail the key components of the IDAS scheme.

1. The residual error tolerant NQAA algorithm for $a(555)$ and $Y$ retrievals: The NQAA algorithm diminishes some effects of residual error. NQAA generates a greater noise-tolerant absorption coefficient $(a(555))$ and a power coefficient of the backscattering coefficient of particles $(Y)$ (Appendix A) than the 


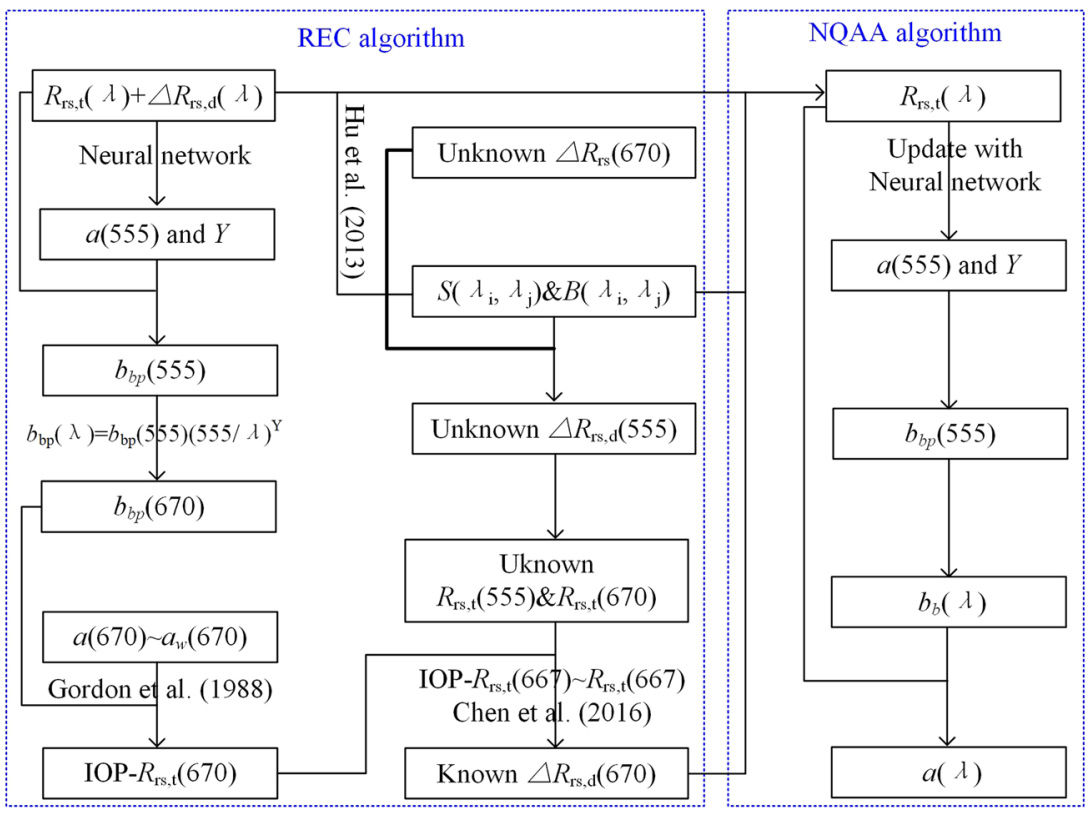

Figure 1. Flow chart for IDAS.

traditional approaches can (e.g., the QAA algorithm) (Lee et al., 2002). Unlike general neural network algorithms structured for IOPs that are quantified from single-mission data (Chen et al., 2014; Ioannou et al., 2013; Jamet et al., 2012), the NQAA algorithm includes the residual errors associated with an imperfect data processing system and sensor noise in error-free $R_{\mathrm{rs}}$ that are spectrally linked by empirical linear relationships (Chen et al., 2016). Because the intermission bias between satellite $R_{\mathrm{rs}}$ is absorbed as part of the residual error (section 2.3), the NQAA algorithm generates consistent intermission $a(555)$ and $Y$ for sensors that spectrally resemble SeaWiFS.

2. The spectral linear relationship of the residual errors for IDAS algorithm: The spectral linear relationship of $\triangle R_{\mathrm{rs}, \mathrm{r}}$ is the key feature of IDAS that accurately retrieves and corrects the residual error (Chen et al., 2016). However, the spectral slope of the linear relationship could vary with different data sources due to changing aerosol properties of the open ocean (Ibrahim et al., 2018; Wang, 2014). Therefore, it is unreasonable to use a fixed spectral linear relationship to correct the residual error. In addition, the IDAS algorithm determines IOPs from satellite $R_{\mathrm{rs}}$ data and from $R_{\mathrm{rs}}$ data that are measured in the field or numerically simulated. The uncertainties in rigorously quality-controlled field $R_{\mathrm{rs}}$ data and simulated $R_{\mathrm{rs}}$ data from a radiative transfer numerical model are much smaller than the uncertainties in $R_{\mathrm{rs}}$ data observed by satellite (Bailey \& Werdell, 2006; Lee et al., 2013). In addition, the spectral characteristics of the residual errors in the field measurements or simulations can be different from the spectral characteristics in the satellite $R_{\mathrm{rs}}$. Consequently, unlike the original IDAS algorithm (Chen et al., 2016), there are three scenarios of the spectral linear relationship of the residual errors for the REC algorithm in IDAS that we use to estimate the residual error. The different input types determine which spectral relationships to use for the residual errors. The three scenarios are as follows:

(1). The slope and bias of the spectral linear relationship are set to zero when the in situ measured or numerically simulated $R_{\mathrm{rs}}$ data are used as inputs for running the IDAS algorithm because the quality of those data is much higher than the satellite data (Bailey \& Werdell, 2006; Lee et al., 2013).

(2). Hu et al. (2013) proposed an approach for determining the spectral relationship of residual errors for each satellite image (one spectral relationship per image) when the satellite $R_{\mathrm{rs}}$ images run the IDAS algorithm because these spatial relationships vary from image to image, even in the oligotrophic open ocean.

(3). The SeaWiFS and MODISA spectral relationships of the residual errors, respectively proposed by Chen et al. (2016) and Hu et al. (2013), run the REC algorithm when Hu et al.'s residual error retrieval method 
fails because there are not enough data (less than 10,000 pixels) for residual error statistical analyses to construct the spectral relationship.

3. Residual error retrievals with known $a(555), Y$, and the spectral relationship of residual errors: For a given $R_{\mathrm{rs}}$ spectrum of any pixel, because the NQAA algorithm accurately determines $a(555)$ and $Y$ at $555 \mathrm{~nm}$, there are two unknowns $\left(b_{\mathrm{b}}(555)\right.$ and $\left.\triangle R_{\mathrm{rs}, \mathrm{r}}(555)\right)$ for the IOPs- $R_{\mathrm{rs}}$ semianalytical relationship that Gordon et al. (1988) proposed. Chen et al. (2016) suggested using the IOPs- $R_{\mathrm{rs}}$ relationship at $670 \mathrm{~nm}$ to algebraically calculate these two unknowns, pixel by pixel, so that there are two unknowns and two equations. When $\triangle R_{\mathrm{rs}, \mathrm{r}}(670)$ is known, $\triangle R_{\mathrm{rs}, \mathrm{r}}$ at short wavelengths can accurately determine with a spectral linear relationship (Chen et al., 2016; Hu et al., 2013). The IDAS algorithm $R_{\mathrm{rs}}, a(555)$, and $Y$ accurately determine intermission consistency (section 2.3) so that, in the end, IDAS improves the intermission consistency of the IOPs products.

\subsection{Key Components of IDAS for Improving Intermission Consistency}

The factors affecting the magnitude of residual error and intermission bias are very complicated (Ahmad et al., 2010; Gordon \& Wang, 1994; Hu et al., 2013), which makes it impossible to completely isolate the residual error or the intermission bias from the total error budget. The IDAS algorithm estimates the residual error in the satellite $R_{\mathrm{rs}}$ spectrum as follows (Chen et al., 2016):

$$
\begin{aligned}
& R_{r s, s, r}(555)=R_{r s, t}(555)+\Delta R_{r s, r}(555) \\
& R_{r s, s, r}(670)=R_{r s, t}(670)+\Delta R_{r s, r}(670)
\end{aligned}
$$

where $R_{\mathrm{rs}, \mathrm{t}}$ refers to the "true" remote sensing reflectance of the reference satellite, and $\triangle R_{\mathrm{rs}, \mathrm{r}}$ represents the residual error. Lastly, $R_{\mathrm{rs}, \mathrm{s}, \mathrm{r}}$ is the remote sensing reflectance observed by the reference satellite. Because we trained the IDAS algorithm with a data set of SeaWiFS wavelengths, we used SeaWiFS as the reference satellite in this study.

For the target satellite, we consider the intermission bias. Equations (1) and (2) are rewritten as follows:

$$
\begin{aligned}
& R_{r s, s, t}(555)=R_{r s, t}(555)+\Delta R_{r s, r}(555)+\Delta R_{r s, b}(555) \\
& R_{r s, s, t}(670)=R_{r s, t}(670)+\Delta R_{r s, r}(670)+\Delta R_{r s, b}(670)
\end{aligned}
$$

where $\triangle R_{\mathrm{rs}, \mathrm{b}}$ represents the intermission bias between target and reference satellite $R_{\mathrm{rs}, \mathrm{t}}$, where $R_{\mathrm{rs}, \mathrm{s}, \mathrm{t}}$ is the remote sensing reflectance observed by the target satellite. Equations (1) and (2) include two unknowns ( $b_{\mathrm{b}}(555)$ and $\triangle R_{\mathrm{rs}, \mathrm{r}}$ ), which are solved algebraically for each satellite $R_{\mathrm{rs}}$ spectrum using the IDAS algorithm (Chen et al., 2016). Because the NQAA algorithm accurately determines $a(555)$, the intermission consistency of the $R_{\mathrm{rs}}$ data mainly depends on the intermission consistency of the $b_{\mathrm{b}}(555)$ data. The dependency occurs because IDAS assumes that $R_{\mathrm{rs}, \mathrm{t}}$ is accurately deduced from the relationship of IOPs with $R_{\mathrm{rs}}$ (Gordon et al., 1988) (Appendix A). However, in addition to residual errors, equations (3) and (4) contain intermission bias. Actually, the intermission bias can be deemed as a small uncertainty for $b_{\mathrm{b}}(555)$ and $\triangle R_{\mathrm{rs}, \mathrm{r}}$ retrievals in IDAS equations. When we apply the IDAS algorithm to the target satellites, the intermission bias propagates into $b_{\mathrm{b}}(555)$ and $\triangle R_{\mathrm{rs}, \mathrm{r}}$ retrievals because equations (3) and (4) are closed equations (called this as IDAS equations constraint). Thus, to understand how the IDAS algorithm improves the intermission consistency between satellite $R_{\mathrm{rs}}$ data, it is necessary to show the impacts of the intermission bias on $b_{\mathrm{b}}(555)$ and $\triangle R_{\mathrm{rs}, \mathrm{r}}$ retrievals in equations (3) and (4).

When we assume that $\xi$ is the portion of intermission bias propagating into the $\triangle R_{\mathrm{rs}, \mathrm{r}}$ retrievals, the remaining intermission bias $\left(\triangle R_{\mathrm{rs}, \mathrm{b}}-\xi\right)$ propagates into the $b_{\mathrm{b}}(555)$ estimates and are expressed as follows:

$$
f^{-1}\left[\Delta b_{b}(\lambda)\right]=-\left[\Delta R_{r s, b}(\lambda)-\xi(\lambda)\right]
$$

$\triangle b_{\mathrm{b}}(555)$ is the increment of the backscattering coefficients caused by the remaining intermission bias and $f$ is the function that propagates the remaining intermission bias into the $b_{\mathrm{b}}$ estimates. When we combine equations (3) and (4) with equation (5) we get the following:

$$
\begin{aligned}
& R_{r s, i d a s}(555)=R_{r s, s, t}(555)+f^{-1}\left[\Delta b_{b}(555)\right]=R_{r s, t, r}(555)+\left[\Delta R_{r s, r}(555)+\xi(555)\right] \\
& R_{r s, i d a s}(670)=R_{r s, s, t}(670)+f^{-1}\left[\Delta b_{b}(670)\right]=R_{r s, t, r}(670)+\left[\Delta R_{r s, r}(670)+\xi(670)\right]
\end{aligned}
$$


where $R_{\mathrm{rs}, \text { idas }}$ is called as $R_{\mathrm{rs}, \mathrm{s}, \mathrm{t}}$ but under constraint of IDAS equations. Hu et al. (2013) and Chen et al. (2016) showed that the residual error has strong wavelength-dependent characteristics that linearly decrease as follows:

$$
\Delta R_{r s, r}(555)=S(555,670) \times \Delta R_{r s, r}(670)+B(555,670)
$$

where $S(555,670)$ and $B(555,670)$ are, respectively, the slope and bias of the linear relationship between the residual errors at 555 and $670 \mathrm{~nm}$. In this study, $S(555,670)$ and $B(555,670)$ dynamically changed with the images and we determined $S(555,670)$ and $B(555,670)$ using $\mathrm{Hu}$ et al. (2013) in an image-by-image manner.

The $\xi$ at 555 and $670 \mathrm{~nm}$ must meet the following relationship requirement because of the closed equation properties:

$$
\xi(555)=S(555,670) \times \xi(670)
$$

When we simplify $\left(\triangle R_{\mathrm{rs}, \mathrm{r}}+\xi\right)$ as $\triangle R_{\mathrm{rs}, \mathrm{u}}$, equations (6) and (7) reduce to the following:

$$
\begin{aligned}
& R_{r s, i d a s}(555)=R_{r s, t, r}(555)+\Delta R_{r s, u}(555) \\
& R_{r s, i d a s}(670)=R_{r s, t, r}(670)+\Delta R_{r s, u}(670)
\end{aligned}
$$

Substituting right term of equations (8)-(11) into equation (A1), $R_{\mathrm{rs} \text {,idas }}$ just below the sea surface $\left(r_{\mathrm{rs}, \text { idas }}\right)$ can be approximated as follows:

$$
\begin{gathered}
r_{r s, i d a s}(555)=\frac{R_{r s, t, r}(555)+S(555,670) \Delta R_{r s, u}(670)-B(555,670)}{0.52+1.7\left[R_{r s, t, r}(555)+S(555,670) \Delta R_{r s, u}(670)-B(555,670)\right]} \\
r_{r s, i d a s}(670)=\frac{R_{r s, t, r}(670)+\Delta R_{r s, u}(670)}{0.52+1.7\left[R_{r s, t, r}(670)+\Delta R_{r s, u}(670)\right]}
\end{gathered}
$$

Combining with equation (A2), $r_{\text {rs,idas }}$ can be rewritten as a function of IOPs:

$$
\begin{aligned}
& r_{r s, i d a s}(555)=0.089 \frac{b_{b, t}(555)}{a(555)+b_{b, t}(555)}+0.1245\left[\frac{b_{b, t}(555)}{a(555)+b_{b, t}(555)}\right]^{2} \\
& r_{r s, i d a s}(670)=0.089 \frac{b_{b, t}(670)}{a(670)+b_{b, t}(670)}+0.1245\left[\frac{b_{b, t}(670)}{a(670)+b_{b, t}(670)}\right]^{2}
\end{aligned}
$$

where $b_{\mathrm{b}, \mathrm{t}}(\lambda)$ is the backscattering coefficient but under IDAS equations constraint, which is equal to the sum of $b_{\mathrm{b}}(\lambda)$ and $\triangle b_{\mathrm{b}}(\lambda)$. Combining equations (12) and (13) with equations (14) and (15), we write the IDAS algorithm for the target satellite as follows:

$$
\begin{gathered}
0.089 \frac{b_{b, t}(555)}{a(555)+b_{b, t}(555)}+0.1245\left[\frac{b_{b, t}(555)}{a(555)+b_{b, t}(555)}\right]^{2}= \\
\frac{R_{r s, t, r}(555)+S(555,670) \Delta R_{r s, u}(670)-B(555,670)}{0.52+1.7\left[R_{r s, t, r}(555)+S(555,670) \Delta R_{r s, u}(670)-B(555,670)\right]} \\
0.089 \frac{b_{b, t}(670)}{a(670)+b_{b, t}(670)}+0.1245\left[\frac{b_{b, t}(670)}{a(670)+b_{b, t}(670)}\right]^{2}= \\
\frac{R_{r s, t, r}(670)+\Delta R_{r s, u}(670)}{0.52+1.7\left[R_{r s, t, r}(670)+\Delta R_{r s, u}(670)\right]}
\end{gathered}
$$

For each satellite $R_{\mathrm{rs}}$ spectrum, there are two unknowns ( $b_{\mathrm{b}, \mathrm{t}}(555)$ and $\left.\triangle R_{\mathrm{rs}, \mathrm{u}}\right)$ in this set of equations that can be solved for. Equations (16) and (17) show that accurate retrievals of $\triangle R_{\mathrm{rs}, \mathrm{u}}$ improve intermission consistency of $b_{\mathrm{b}}$, which makes the intermission $R_{\mathrm{rs}}$ more consistent. When $a(555)$ can be "fixed" by NQAA algorithm with high accuracy (Chen et al., 2016), the uncertainty including residual error and intermission bias would propagate to $b_{\mathrm{b}}(555)$ estimates following the relationship of IOPs with $R_{\mathrm{rs}}$ (Gordon 
et al., 1988). As a result, the IOPs data from reference satellite are easy to intermission inconsistent with the target satellite. The IDAS algorithm can remove most residual error and partial intermission bias for IOPs estimates, thus can provide intermission consistent IOPs data. It is worthy note that $\xi$ usually does not equal $\triangle R_{\mathrm{rs}, \mathrm{b}}$, so IDAS suppresses most of the effects of the intermission difference, rather than eradicating it completely.

\subsection{Statistical Evaluation}

In this study, we assessed the accuracy of the IOPs retrieval algorithms using the mean absolute percent difference (MAPD), root-mean-square of log transformed difference $\left(\mathrm{RMSD}_{\mathrm{log}}\right)$, mean ratio value $(\mathrm{MRV})$ of SeaWiFS to MODISA ocean color products, and coefficient of variation (CV). These statistics are expressed as follows:

$$
\begin{gathered}
M R V=\sum_{k=1}^{N} \frac{1}{N} x_{e, k} / \sum_{k=1}^{M} \frac{1}{N} x_{r, k} \\
M A P D=\frac{1}{N} \sum_{k=1}^{N}\left|\frac{x_{e, k}-x_{r, k}}{x_{r, k}}\right| \\
C V=\frac{\sqrt{\sum_{i=1}^{3} \sum_{j=1}^{3}\left(x_{e, i, j}-x_{r, i, j}\right)^{2}}}{x_{r, m}} \\
R M S D_{\log }=\sqrt{\frac{1}{N} \sum_{k=1}^{N}\left[\log \left(x_{e, k}\right)-\log \left(x_{r, k}\right)\right]^{2}} \\
x_{r}=\operatorname{slope\times x_{e}+bias} \\
\delta_{g}=\sqrt{\frac{1}{N} \sum_{k=1}^{N}\left(\frac{x_{e, k}-x_{r, k}}{x_{r, k}}\right)^{2}}
\end{gathered}
$$

where $x_{\mathrm{e}, \mathrm{k}}$ is the algorithm-estimated IOPs product of the $k$ th element from the field-measured or satelliteobserved $R_{\mathrm{rs}} \cdot x_{\mathrm{r}, \mathrm{k}}$ is the equivalent product of the $k$ th element provided by Hydrolight (radiative transfer numerical model), in situ measurements, or derived from the satellite-observed $R_{\mathrm{rs}}$ of our reference satellite (SeaWiFS) in this study. $N$ is the number of elements. $\mathrm{x}_{\mathrm{r}, \mathrm{m}}$ is the mean value of $x_{\mathrm{r}, \mathrm{k}}$ for a $3 \times 3$ pixel box. The "slope" and "bias" represent the slope and intercept of the linear relationship between the field-measured and algorithm-estimated IOPs products and are determined using least squares. $g$ and $\delta_{\mathrm{g}}$ are the vicarious adjustment gain factor and related standard deviations, respectively, that Gordon (1998) and Zibordi et al. (2015) proposed. The annual mean MRV is the ratio of the annual mean SeaWiFS IOPs or $R_{\mathrm{rs}}$ to the annual mean MODISA IOPs or $R_{\mathrm{rs}}$.

\section{Results}

\subsection{Testing With a Simple Synthetic Data Set}

We used daily composite SeaWiFS and MODISA Level-3 images from 2006 to compare SeaWiFS $R_{\mathrm{rs}}$ with MODISA $R_{\mathrm{rs}}$. The composite images were of the annual mean $R_{\mathrm{rs}}, g$, and $\delta_{\mathrm{g}}$ for the global ocean. We computed $g$ and $\delta_{\mathrm{g}}$ with equations (23) and (24) (Figure 2).

We found that the significant spatial trends in these two satellite data sets were consistently distributed, but the trends exhibited some differences. Overall, the SeaWiFS $R_{\mathrm{rs}}$ were higher than MODISA's, but the MODISA $R_{\mathrm{rs}}$ images were spatially smoother than the SeaWiFS $R_{\mathrm{rs}}$ images. Specifically, the global annual mean gain factors were 1.028, 0.995, 1.092, and 1.470 at 443, 490, 555, and $670 \mathrm{~nm}$, respectively. In other words, the SeaWiFS $R_{\mathrm{rs}}$ data were annually $2.8 \%, 9.2 \%$, and $47.0 \%$ higher than the MODISA $R_{\mathrm{rs}}$ data, respectively, at 443, 555, and $670 \mathrm{~nm}$, but annually $0.5 \%$ lower than the MODISA $R_{\mathrm{rs}}$ data at $490 \mathrm{~nm}$. The higher 

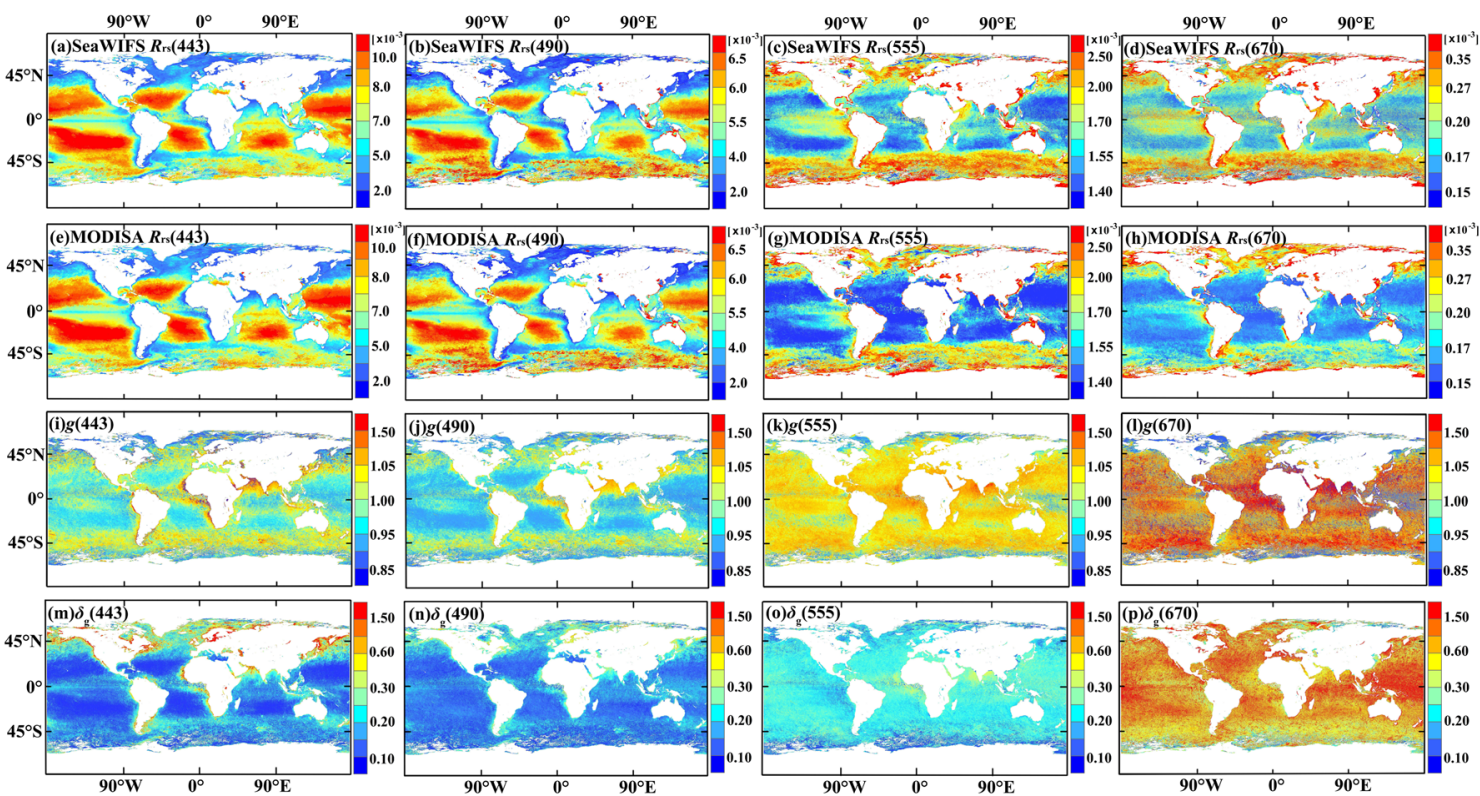

Figure 2. Climatological yearly mean (a-d) SeaWiFS $R_{\mathrm{rs}}(\lambda)$, (e-h) MODISA $R_{\mathrm{rs}}(\lambda)$, (i-l) $g(\lambda)$, and (m-p) $\delta_{\mathrm{g}}(\lambda)$ at $443,490,555$, and $670 \mathrm{~nm}$ in the global oceans. The yearly mean data are merged from the daily Level-3 data from 2006.

gain factors (greater than 1.05) were in the coastal zones and subtropical and tropical oceans, while the lower gain factors (less than 0.95) were in the midlatitudes and Arctic and Antarctic Oceans. Gordon and Voss (1999) suggested that $\pm 5 \%$ errors in satellite $R_{\mathrm{rs}}$ data could result in $\pm 35 \%$ errors in chlorophyll-a concentration retrievals. Therefore, an intermission difference in $R_{\mathrm{rs}}$ data greater than $5 \%$ would inevitably influence the intermission consistency of the ocean color products derived from the multimission satellite system.

To show how IDAS performed in reducing the intermission bias in REC, we looked at the intermission pixelby-pixel differences (SeaWiFS $R_{\mathrm{rs}}$ minus MODISA $R_{\mathrm{rs}}$ ) from the 2006 SeaWiFS and MODISA daily Level-3 data over the oligotrophic Northwest Atlantic Subtropical Ocean $\left(20^{\circ}\right.$ to $30^{\circ} \mathrm{N}, 50^{\circ}$ to $\left.60^{\circ} \mathrm{W}\right)$. Figure 3 shows the spectral relationship of $\triangle R_{\mathrm{rs}, \mathrm{d}}$ among the visible bands (a total of 365 images and 242,708 valid pixels), indicating that $\triangle R_{\mathrm{rs}, \mathrm{d}}$ was strongly spectrally dependent and the coefficients of determination $\left(R^{2}\right)$ between SeaWiFS and MODIS $R_{\mathrm{rs}}$ were greater than 0.7 .

For each Hydrolight $R_{\mathrm{rs}}$ spectrum, we generated a random $\triangle R_{\mathrm{rs}, \mathrm{d}}(670)$ value using a Gaussian shape (calculated from $\triangle R_{\mathrm{rs}, \mathrm{d}}(670)$ in Figure 3d), and then we extrapolated to $\triangle R_{\mathrm{rs}, \mathrm{d}}$ at the short-visible bands using the relationships shown in Figure 3. We added those short-visible bands to all bands of the Hydrolight $R_{\mathrm{rs}}$ data that had the residual error included. Knowing that the intermission difference was the sum of the residual error and the intermission bias, we used the intermission difference to replace the intermission bias because of the difficulty in separating the intermission bias from the intermission difference.

Due to the influences of $\triangle R_{\mathrm{rs}, \mathrm{b}}$ and $\triangle R_{\mathrm{rs}, \mathrm{r}}$, the error-included $R_{\mathrm{rs}}$ data were quite different from the errorfree $R_{\mathrm{rs}}$ data whose MAPD at $555 \mathrm{~nm}$ reached $35.51 \%$ (Figure 4a), which impacted retrieving IOPs without any correction. As a result, after applying the NQAA algorithm to the original error-included $R_{\mathrm{rs}}$ data, the NQAA algorithm generated $12.25 \%$ and $34.72 \%$ MAPD values for the $a(443)$ and $b_{\mathrm{b}}(555)$ retrievals, respectively (Figures $4 \mathrm{~b}$ and $4 \mathrm{c}$ ). However, after we corrected the data with the IDAS algorithm, the data quality of the $R_{\mathrm{rs}}$ notably improved, with the MAPD at $555 \mathrm{~nm}$ decreasing to $9.99 \%$ (Figure $4 \mathrm{~d}$ ).

Using these improved $R_{\mathrm{rs}}$ data as inputs, the NQAA algorithm produced more consistent IOPs with known values than the NQAA algorithm with the original error-included $R_{\mathrm{rs}}$ data (Figures $4 \mathrm{e}$ and $4 \mathrm{f}$ ). Specifically, the MAPD values of the IDAS algorithm were $9.22 \%$ and $12.19 \%$ for $a(443)$ and $b_{\mathrm{b}}(555)$, respectively, which were $3.03 \%$ and $22.53 \%$ lower than the NQAA algorithm with the original error-included $R_{\mathrm{rs}}$ data. Compared to the spectral relationship of residual errors that $\mathrm{Hu}$ et al. (2013) and Chen et al. (2016) proposed, we found 

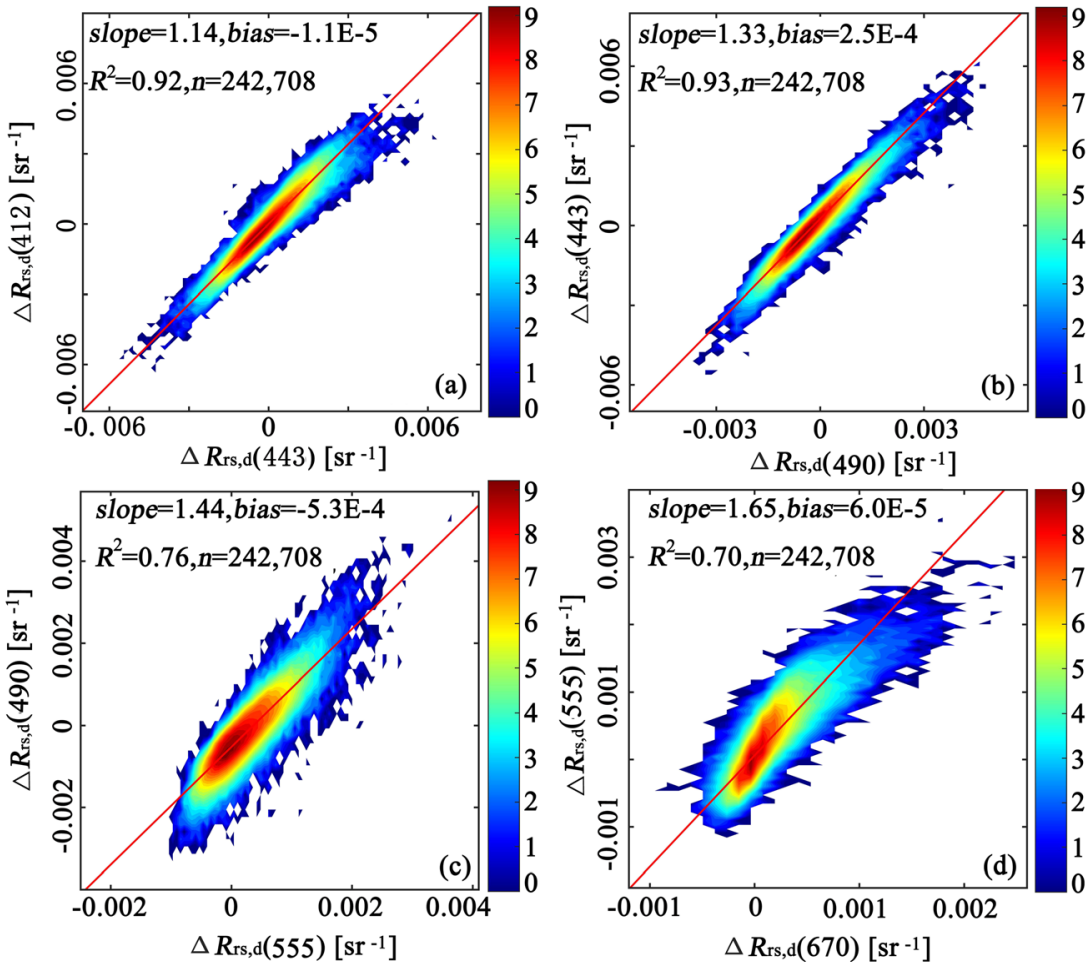

Figure 3. Spectral relationship of $\triangle R_{\mathrm{rs}, \mathrm{d}}$ obtained from 365 daily Level-3 SeaWiFS and MODISA $R_{\mathrm{rs}}$ images from 2006, corrected for residual error, over the North Atlantic Gyre $\left(20^{\circ}\right.$ to $30^{\circ} \mathrm{N}, 50^{\circ}$ to $\left.60^{\circ} \mathrm{W}\right)$.

that the wavelength-dependent characteristics of $\triangle R_{\mathrm{rs}, \mathrm{d}}$ (including slope and bias of the linear relationship) differed slightly from the residual error in the open ocean. However, after processing with the IDAS algorithm, most $\triangle R_{\mathrm{rs}, \mathrm{d}}$ plus $\triangle R_{\mathrm{rs}, \mathrm{r}}$ in the satellite $R_{\mathrm{rs}}$ were removed and gave us consistent IOPs (Figures $4 \mathrm{~b}$ and $4 \mathrm{~d}$ ).
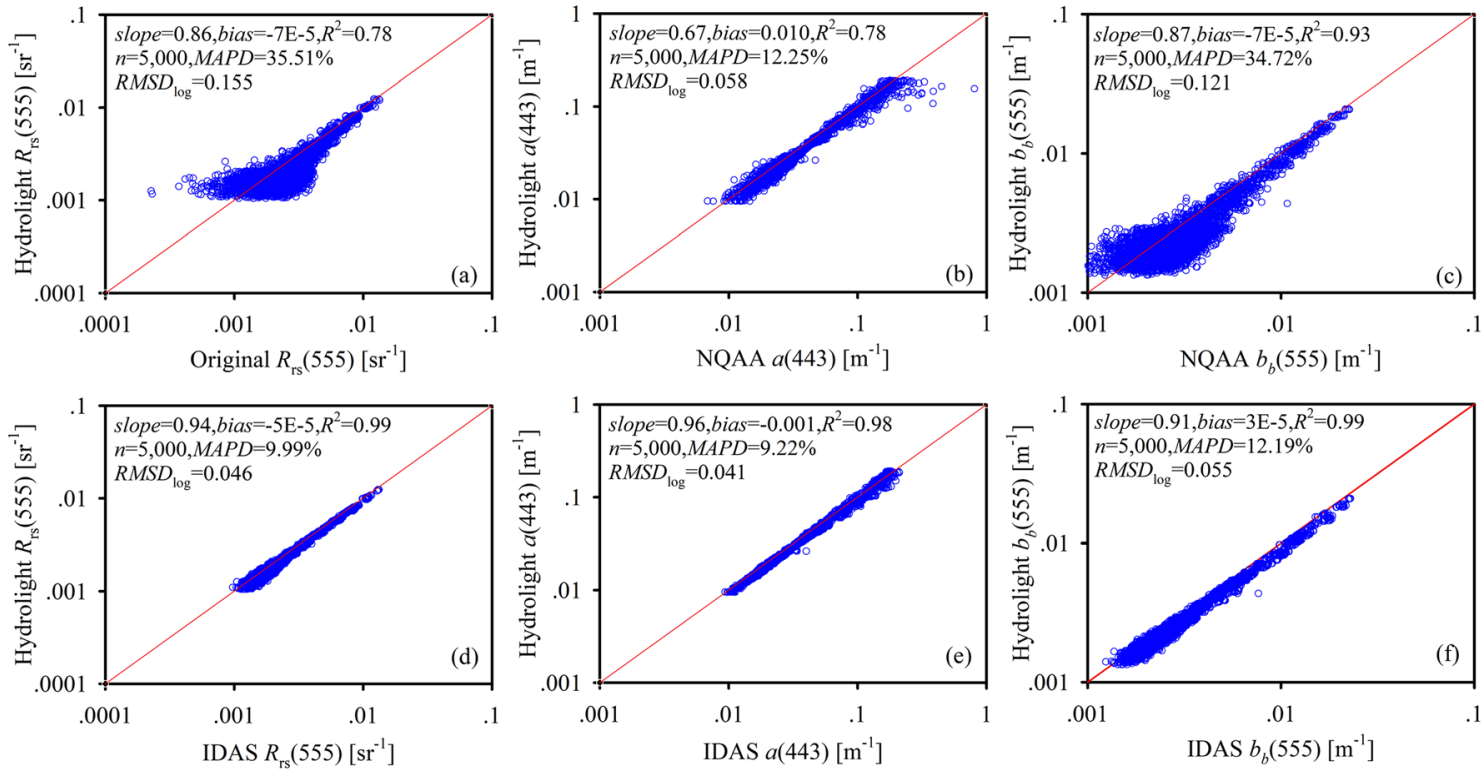

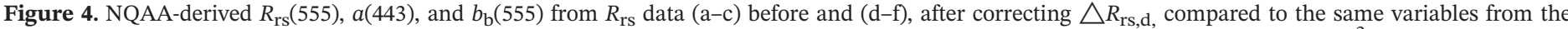
Hydrolight simulations. The Hydrolight data set had 5,000 data points with chlorophyll-a concentration varying between $0.01 \mathrm{and} 2 \mathrm{mg} / \mathrm{m}^{3}$. We determined the IOPs by chlorophyll-a and used the IOPs relationship included in Hydrolight 5.2 (Mobley \& Sundman, 2013). 

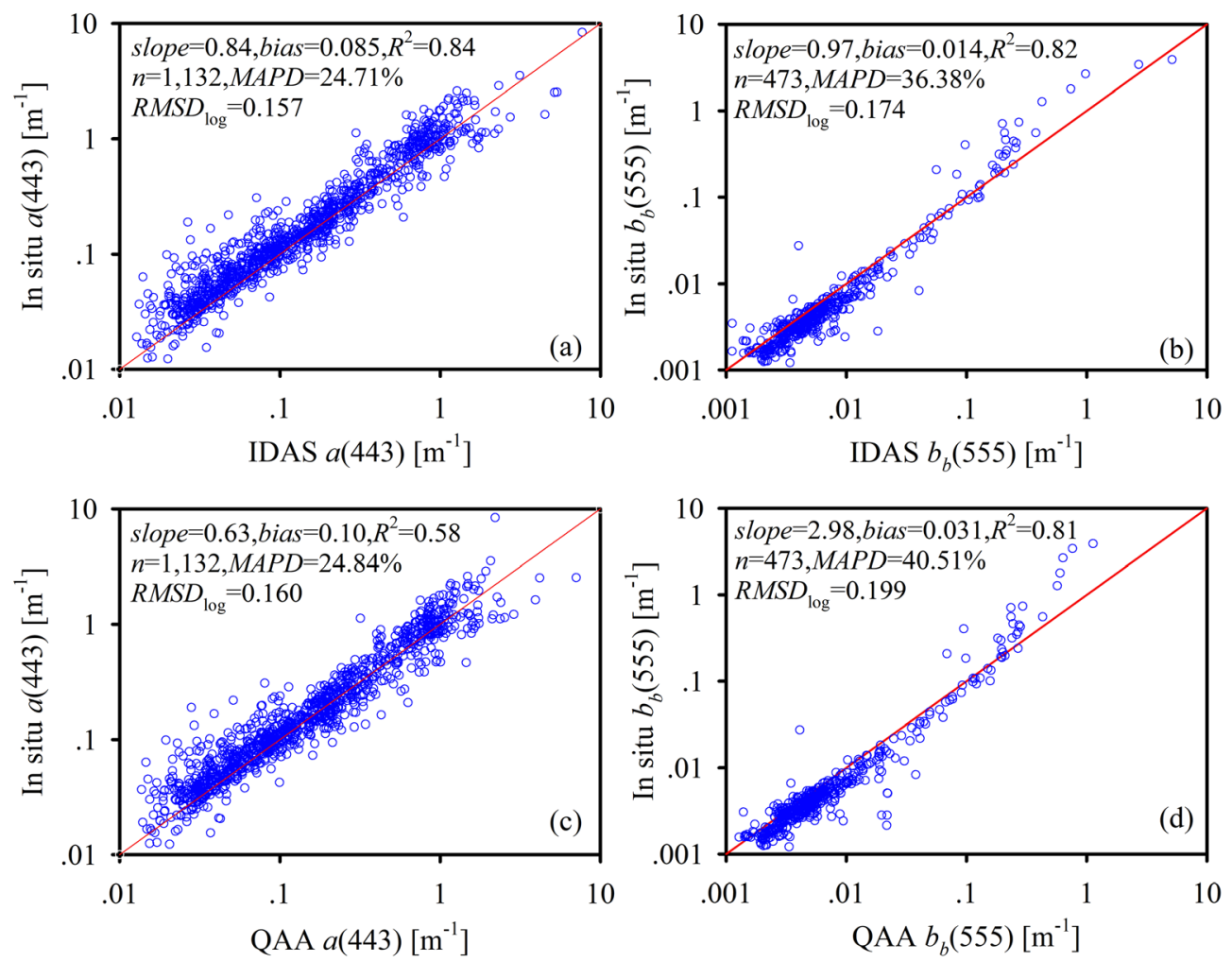

Figure 5. Comparing known and model-derived $a(443)$ and $b_{b}(555)$ for the in situ data set. (a) and (b) are results from the IDAS model, and (c) and(d) are results from the QAA model.

\subsection{Testing With Sample Point Data}

Chen et al. (2016) developed the NQAA algorithm, and their results showed that the algorithm performed well in quantifying $a(555)$ and $Y$, even from $R_{\mathrm{rs}}$ data that had noise. Therefore, in this study, we did not refine the neural network of the NQAA algorithm. $Y$ was not a standard product in the NASA ocean color data so we could not evaluate how IDAS performed at retrieving $Y$. Instead, we looked at how well IDAS performed at retrieving $a(443)$ because $Y$ is an important parameter for determining $a(443)$ (Gordon et al., 1988).

We evaluated the IDAS algorithm's performance by comparing $a(443)$ and $b_{\mathrm{b}}(555)$, as predicted by the IDAS and QAA algorithms (version 5), with equivalent field measurements (Table 2). Based on 1132 samples for $a(443)$ and 473 samples for $b_{\mathrm{b}}(555)$ collected from NOMAD, Figure 5 shows that the IDAS and QAA algorithm-derived $a(443)$ and $b_{\mathrm{b}}(555)$ agreed very well with the measured $a(443)$ and $b_{\mathrm{b}}(555)$. Specifically, the MAPD values did not exceed $41 \%$, and the $R^{2}$ values were greater than 0.58 .

After comparing the IDAS algorithm results to the QAA algorithm results, we found that IDAS was more effective at retrieving IOPs. The $R^{2}$ values for IDAS were greater than 0.82 and were higher than the QAA $R^{2}$ for the $a(443)$ and $b_{\mathrm{b}}(555)$ retrievals. After using IDAS, the MAPD values decreased by $0.07 \%$ and were 4.13\% greater than the QAA algorithm's MAPD for the $a(443)$ and $b_{\mathrm{b}}(555)$ retrievals. At the higher end $\left(a(443)>1.1 \mathrm{~m}^{-1}\right.$ or $\left.b_{\mathrm{b}}(555)>0.1 \mathrm{~m}^{-1}\right)$, the IDAS-derived $a(443)$ and $b_{\mathrm{b}}(555)$ versus the field-measured $a(443)$ and $b_{\mathrm{b}}(555)$ were much closer to a 1:1 line than when we used the QAA algorithm. The difference between the two algorithms at the higher end was because some band ratio approaches employed in the QAA algorithm just reduce effects of the backscattering coefficients (refer to the $R_{\mathrm{rs}}$-IOPs relationship for $a(555)$ retrieval in the QAA algorithm), rather than removing the effects of the backscattering coefficients for $a(555)$ retrievals in turbid waters (Chen et al., 2014). Due to the low number of suspended particles in the open ocean (Morel \& Prieur, 1977), the impacts of the backscattering coefficients on QAA performance would be much weaker than in turbid waters (Chen et al., 2014). Therefore, $a(443)$ and $b_{\mathrm{b}}(555)$ could be accurately retrieved by the IDAS and QAA algorithms for the open ocean. However, this conclusion 
might only be valid for strictly quality controlled optical data due to the highly sensitive nature of the band ratio approach to the residual error in ocean color data.

\subsection{Assessing the Algorithms Using Satellite Images}

If we were to use the IDAS algorithm to accurately determine $a(555)$ (Chen et al., 2016), the uncertainties in satellite $R_{\mathrm{rs}}(555)$ would propagate into the $b_{\mathrm{b}}(555)$ data because of the IOPs versus $R_{\mathrm{rs}}$ semianalytical relationship at $555 \mathrm{~nm}$ that Gordon et al. (1988) first noted (equations (16) to (17)). Therefore, we examined how IDAS performed in achieving consistent IOPs products from multiple satellites for the open ocean by checking their intermission consistency for $b_{\mathrm{b}}(555)$ instead of using $a(555)$. Note that we used the MODISA 555-nm band because the spectral response function of this band was much closer to SeaWiFS $555 \mathrm{~nm}$ than the MODISA 547-nm band. Additionally, the MODISA $R_{\mathrm{rs}}(555)$ is also part of the standard data in the Level-2 GAC data set, even though this band was not originally designed for ocean color measurements. Showing the impacts of band difference on the performance of the IDAS algorithm was beyond the scope of our current study.

\subsubsection{Evaluating and Comparing Algorithms Using a Single-Mission SeaWiFS Image}

The accuracy of satellite $b_{\mathrm{b}}(555)$ products that the QAA or IDAS algorithms provide are affected by the accuracy of satellite $R_{\mathrm{rs}}$ and by the performance of satellite $a(555)$, which also depends on the accuracy of satellite $R_{\mathrm{rs}}$. Therefore, the $b_{\mathrm{b}}(\lambda)$ products are more sensitive to residual error and intermission bias in satellite $R_{\mathrm{rs}}$ than $a(\lambda)$ (Chen et al., 2016).

Figure 6 shows the $b_{\mathrm{b}}(555)$ that IDAS and QAA produced from the SeaWiFS images collected on 20 February 1998 over the Sargasso Sea, an oligotrophic region. Due to the inherent residual error, the QAA $b_{\mathrm{b}}(555)$ image was patchy and speckled (Figure 6a). Because we retrieved and corrected for the residual error, IDAS generated better estimates of $b_{\mathrm{b}}(555)$ than the QAA algorithm did (Figures $7 \mathrm{a}$ and $7 \mathrm{~b}$ ). Compared to the QAA $b_{\mathrm{b}}(555)$ image, the IDAS $b_{\mathrm{b}}(555)$ were more tightly distributed (Figure 6e), and the standard deviations and CV values were significantly reduced ( $>50 \%$ ) (Figures $6 \mathrm{c}-6 \mathrm{f}$ ). Because the band ratio algorithm is sensitive to the residual errors in satellite data, there were many pixels in the QAA $b_{\mathrm{b}}(555)$ image (Figures 6a, 6c, and 6f) whose CV values were very large (greater than 0.8 ) because some adjacent pixels were contaminated by clouds. However, when we used IDAS, the $b_{\mathrm{b}}(555)$ data quality improved significantly. Specifically, we found much fewer pixels with high CV values in the IDAS $b_{\mathrm{b}}(555)$ image (Figures $6 \mathrm{~d}$ and $6 \mathrm{f}$ ). Note that we used the spectral relationship of the residual error in the second scenario in section 2.2 in the IDAS algorithm for retrieving $b_{\mathrm{b}}(555)$; thus, the mean CV value of the IDAS $b_{\mathrm{b}}(555)$ in Figure $6 \mathrm{f}$ was much lower than the results found by Chen et al. (2016).

\subsubsection{Evaluating and Comparing Algorithms Using Single-Synchronized Images}

We used SeaWiFS and MODISA Level-2 image data of the North Atlantic Gyre ( $17^{\circ}$ to $27^{\circ} \mathrm{N}, 54^{\circ}$ to $60^{\circ} \mathrm{W}$ ), from 12 October 2006 to see if we can apply IDAS to retrieve $b_{\mathrm{b}}(555)$ from open blue water. Figure 7 compares $b_{\mathrm{b}}(555)$ from the SeaWiFS and MODISA $R_{\mathrm{rs}}$ data derived using IDAS and QAA. We found that the SeaWiFS QAA $b_{\mathrm{b}}(555)$ image exhibited significant noise speckling with much discontinuity and patchiness (Figure 7a). The speckling in the images was primarily caused by the cloud adjacency, and the patchiness was more likely associated with atmospheric correction errors, whitecap correction errors, digitization noise-included errors, and other factors (Hu et al., 2013).

Even though the MODISA and SeaWiFS sensors have some similar central wavelengths and spectral response characteristics, they exhibit differences in bandwidth, digitized bytes, and signal-to-noise ratio. Because MODISA is 12-bit digitized as opposed to 10 bit for SeaWiFS, and MODISA has approximately twice the signal-to-noise ratio than SeaWiFS (Gordon \& Voss, 1999), the MODISA QAA $b_{\mathrm{b}}(555)$ was spatially smoother than the equivalent product derived from SeaWiFS (Figures 7a to 7b).

Because SeaWiFS has larger spatial resolution than MODISA, the pixels in the SeaWiFS images are more likely to include a small fraction of bright cloud or other bright targets; yet the standard ocean color data processing system still considers these brighter pixels to be normal pixels and exports them to the Level-2 products. As a result, our SeaWiFS images covered more area than MODISA images did (Figures 7a to 7b), but there was more patchiness near cloud edges in the SeaWiFS images (Figure 7b), which resulted in many large $b_{\mathrm{b}}(555)$ values (greater than $0.004 \mathrm{~m}^{-1}$ ) in the histograms in Figure 7 (Figure 7a). In contrast to the patchy and speckled QAA-produced $b_{\mathrm{b}}(555)$ image, the IDAS $b_{\mathrm{b}}(555)$ in Figures 7e to $7 \mathrm{f}$ was much smoother, 


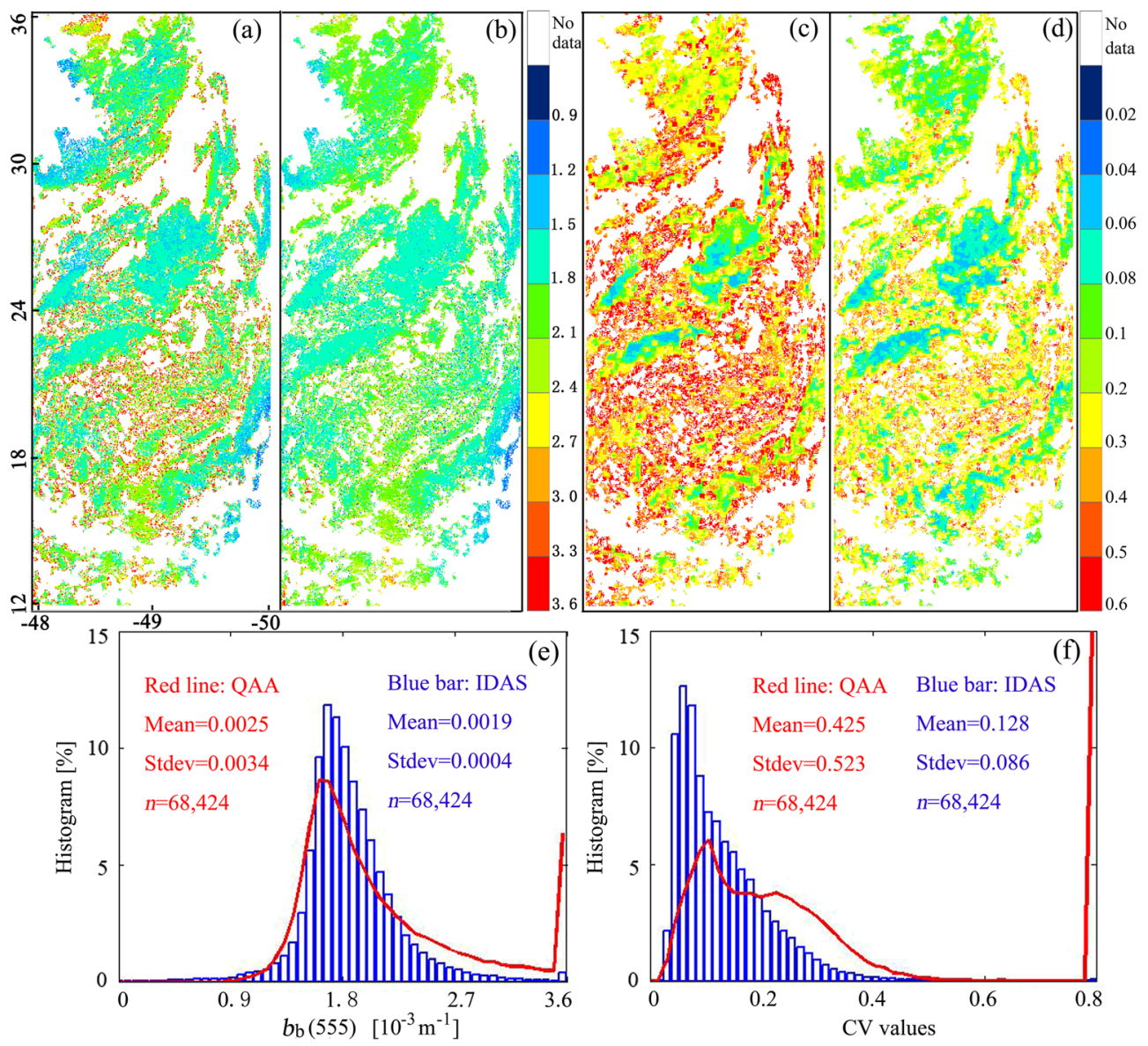

Figure 6. $b_{\mathrm{b}}(555)$ derived with IDAS and QAA using SeaWiFS Level-2 data over the Sargasso Sea from 20 February 1998: (a) and (b) are the QAA and IDAS $b_{\mathrm{b}}(555)$ images $\left(10^{-3} \mathrm{~m}^{-1}\right)$; (c) and (d) are the CV values of the QAA and IDAS $b_{\mathrm{b}}(555)$ images; (e) and (f) are the histograms of $b_{\mathrm{b}}(555)$ and CV values of the $b_{\mathrm{b}}(555)$ images. White represents clouds. The "red line" represents the results from the IDAS algorithm, while the "blue bar" represents the results from the QAA algorithm. All pixels with $R_{\mathrm{rs}}(\lambda)>0$ were analyzed.

and the IDAS $b_{\mathrm{b}}(555)$ distribution was more spatially coherent, even near cloud edges. Specifically, when we used the IDAS algorithm for the SeaWiFS and MODISA images, IDAS produced a narrow and sharp frequency distribution of $b_{\mathrm{b}}(555)$ compared to the distribution derived from the QAA algorithm (Figures $7 \mathrm{~d}$ and $7 \mathrm{~h}$ ). The MRV values of $b_{\mathrm{b}}(555)$ were 1.049 and 1.424 for the IDAS and QAA algorithms, respectively. The MAPD values for the pixel-by-pixel comparison of the $b_{\mathrm{b}}(555)$ produced by IDAS and QAA were $29.63 \%$ and $14.42 \%$, respectively. In other words, the MRV value of $b_{\mathrm{b}}(555)$ produced by the IDAS algorithm was 0.375 (the latter minus the former) lower than the MRV of $b_{\mathrm{b}}(555)$ produced by the QAA algorithm. IDAS generated an intermission difference within $\pm 5 \%$ for this pair of singlesynchronized images.

Figure 8 shows the residual errors at $670 \mathrm{~nm}$ derived from the SeaWiFS and MODISA Level- $2 R_{\mathrm{rs}}$ data using IDAS. The residual errors mainly ranged from $-10^{-4}$ to $10^{-4} \mathrm{sr}^{-1}$. The SeaWiFS images were patchy and speckled and were not spatially coherent or smooth. In comparison, the MODISA images were spatially smoother than the SeaWiFS images (Figures $8 \mathrm{a}$ and $8 \mathrm{~b}$ ) because the instrument quality of the former is much higher than that of the latter (Gordon \& Voss, 1999). The mean and standard deviation of the SeaWiFS $R_{\mathrm{rs}}$, $\mathrm{r}(670)$ were $0.74 \times 10^{-4}$ and $3.02 \times 10^{-4} \mathrm{sr}^{-1}$, respectively, which were approximately five times larger than the mean and standard deviation of the MODISA $R_{\mathrm{rs}, \mathrm{u}}(670)$ (Figures $8 \mathrm{~d}$ and $8 \mathrm{e}$ ).

If we know the SeaWiFS $R_{\mathrm{rs}, \mathrm{r}}(670)$ and MODISA $R_{\mathrm{rs}, \mathrm{u}}(670)$, then we can approximately calculate the intermission difference. We found that the mean and standard deviation of $R_{\mathrm{rs}, \mathrm{d}}(670)$ were $0.31 \times 10^{-4}$ and $2.40 \times$ $10^{-4} \mathrm{sr}^{-1}$, respectively. Figures $8 \mathrm{c}$ and $8 \mathrm{f}$ show that the intermission difference was spatially distributed 

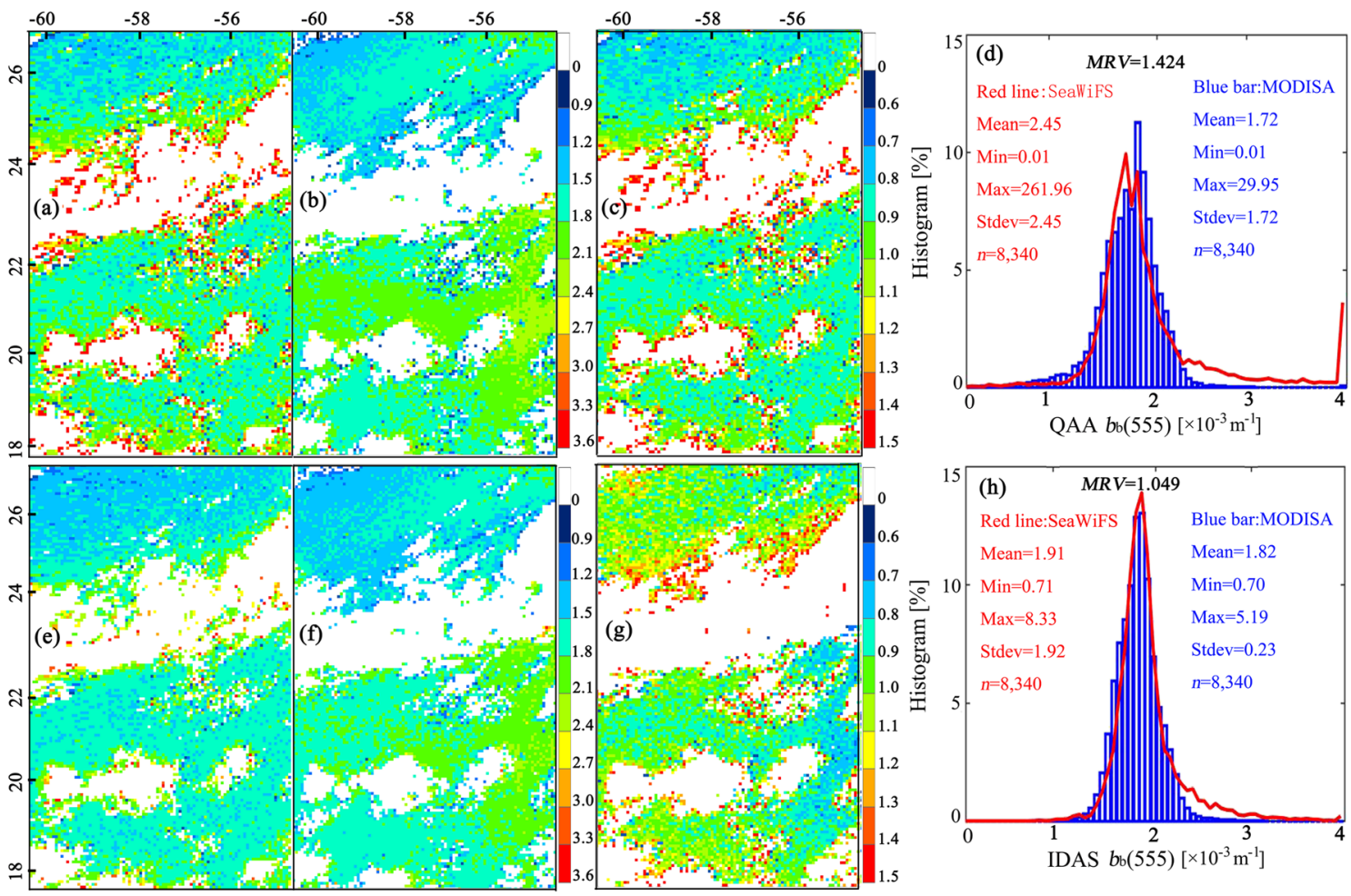

Figure 7. Comparison of $b_{\mathrm{b}}(555)$ retrieved from SeaWiFS with MODISA Level-2 data over the North Atlantic Gyre (54-60 $\left.\mathrm{W}, 17-27^{\circ} \mathrm{N}\right)$ on 12 October 2006 . (a) and (b) are the QAA $b_{\mathrm{b}}(555)$ images derived from SeaWiFS and MODISA $R_{\mathrm{rs}}$ data $\left(\times 10^{-3} \mathrm{~m}^{-1}\right)$; (e) and (f) are the IDAS $b_{\mathrm{b}}(555)$ images derived from SeaWiFS and MODISA $R_{\mathrm{rs}}$ data $\left(\times 10^{-3} \mathrm{~m}^{-1}\right)$; (c) and (g) are the ratio of SeaWiFS to MODISA $b_{\mathrm{b}}(555)$ for QAA and IDAS (dimensionless); (d) and (h) are the histograms of QAA and IDAS $b_{\mathrm{b}}(555)$ images. The "red line" represents the results from SeaWiFS images, and the "blue bar" represents the results from MODISA images. The white in the $b_{\mathrm{b}}(555)$ images represents clouds, while that in the ratio images represents clouds existing either in MODISA or SeaWiFS. All pixels with $R_{\mathrm{rs}}(\lambda)>0$ were analyzed.

more like the SeaWiFS $R_{\mathrm{rs}, \mathrm{r}}(670)$ than the MODSIA $R_{\mathrm{rs}, \mathrm{u}}(670)$. For example, there were many noisy pixels around the cloud edges in the intermission difference distribution, which was consistent with what we saw in the SeaWiFS images. The similarity of the intermission difference and statistics with the SeaWiFS $R_{\mathrm{rs}, \mathrm{r}}(670)$ distribution and statistics implies that the intermission difference between SeaWiFS and MODISA $R_{\mathrm{rs}}$ data was mainly from the SeaWiFS satellite due to its low instrumental quality.

\subsubsection{Evaluating and Comparing Algorithms Using Multisynchronized Images}

For a single perfectly calibrated ocean color sensor, the radiance or reflectance at the top of atmosphere is ideally error free so that the only source for error in the satellite-observed $R_{\mathrm{rs}}$ data would originate from atmospheric correction and other external influences. However, for multiple calibrated ocean color sensors, the sources of uncertainty are more complicated than for a single calibrated sensor, which leads to differences in the ocean color data between missions. In addition to imperfect atmospheric correction, band output effects, spatial scaling effects, spectral response functions (Mélin et al., 2017), ratio of signal-to-noise level (Gordon \& Voss, 1999; Gordon \& Wang, 1994), interval time for satellite overpass (Bailey \& Werdell, 2006), on-orbit radiance calibration (Gordon, 1998) impact the consistency of the ocean color data observed by multiple missions (Gordon, 1998).

Figures 9a to 9c compare the original 2009 SeaWiFS Level- $2 R_{\mathrm{rs}}$ data with 2009 MODISA Level- $2 R_{\mathrm{rs}}$ from the North Atlantic Gyre. From the figures, we see that a clear difference exists. Specifically, the annual mean MRV values for SeaWiFS $R_{\mathrm{rs}}$ were 1.070, 1.278, and 2.176, respectively, at 443, 555, and $670 \mathrm{~nm}$, so that the annual mean SeaWiFS $R_{\mathrm{rs}}$ were $7.0 \%, 27.8 \%$, and $117.6 \%$ higher than the MODISA $R_{\mathrm{rs}}$. The difference was significantly large and exceeded the required maximum difference for climate change trend analysis of the open ocean at green and red wavelengths (Gregg et al., 2009; Mélin, 2016). After processing with IDAS, the annual MRV values for SeaWiFS $R_{\mathrm{rs}}$ decreased to 1.002, 1.032, and 1.067, respectively, at 443, 555, and $670 \mathrm{~nm}$ (Figures $9 \mathrm{~d}$ to 9f). We attributed the notable improvement to the effectiveness of IDAS 


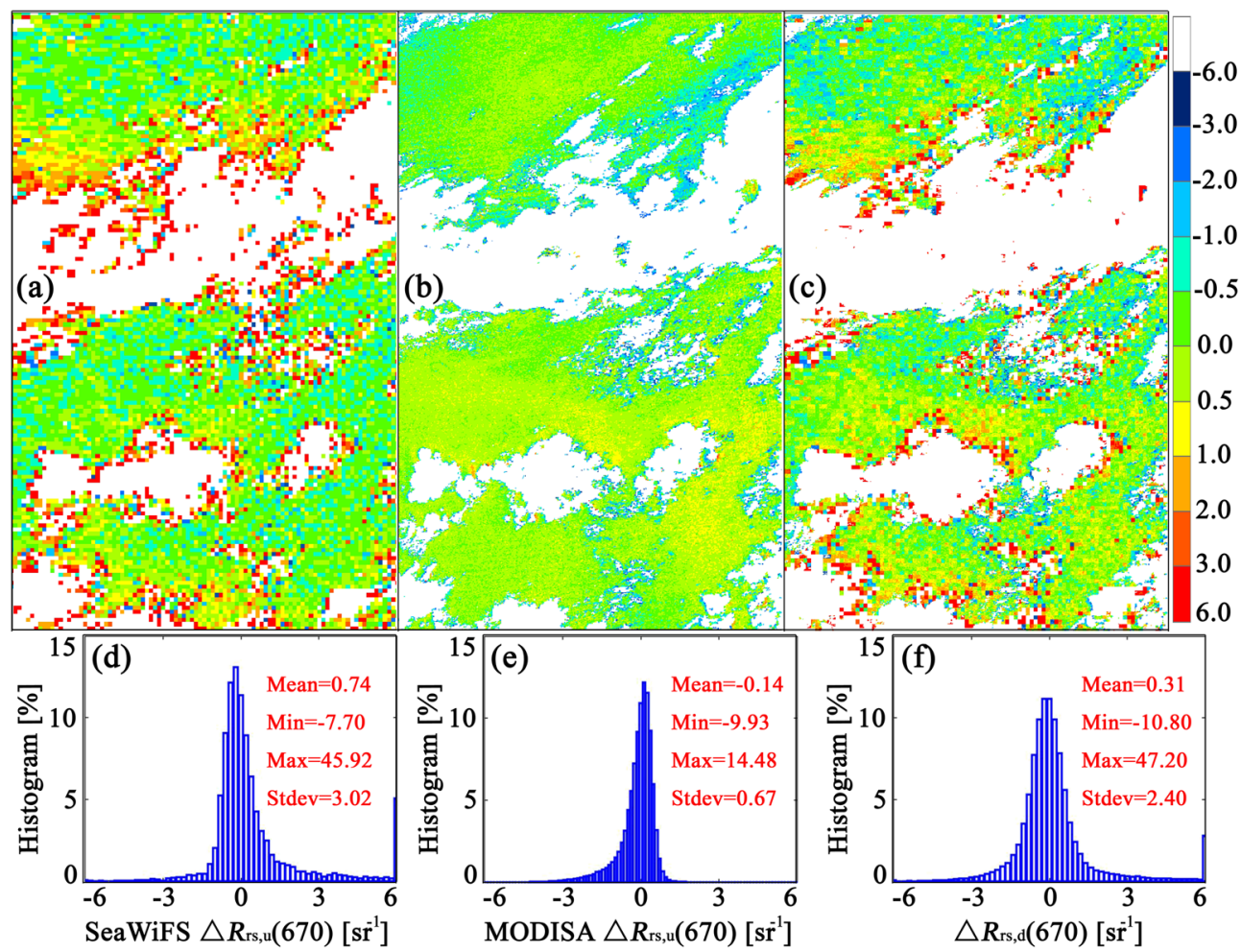

Figure 8. Same as Figure 7 but for residual error and intermission difference for SeaWiFS and MODISA Level-2 data over the North Atlantic Gyre $\left(54^{\circ}\right.$ to $60^{\circ} \mathrm{W}, 17^{\circ}$ to $27^{\circ} \mathrm{N}$ ) on 12 October 2006. (a) is SeaWiFS residual error at $670 \mathrm{~nm}\left(\times 10^{-4} \mathrm{~m}^{-1}\right)$; (b) is MODISA residual error plus partial intermission bias propagated into residual error retrievals by IDAS $\left(\times 10^{-4} \mathrm{~m}^{-1}\right)$; (c) is the intermission difference between SeaWiFS and MODISA at $670 \mathrm{~nm}\left(\times 10^{-4} \mathrm{~m}^{-1}\right)$; and (d)-(f) are the corresponding histograms in (a)-(c). The white in the $b_{\mathrm{b}}(555)$ images represents clouds, while that in the ratio images represents clouds existing either in MODISA or SeaWiFS. All pixels with $R_{\mathrm{rs}}(\lambda)>0$ were analyzed.

in removing the residual errors and partial intermission bias in $R_{\mathrm{rs}}$. Specifically, at the higher end of the red and green wavelengths $\left(R_{\mathrm{rs}}(555)>0.003 \mathrm{sr}^{-1}\right.$ or $\left.R_{\mathrm{rs}}(670)>0.0003 \mathrm{sr}^{-1}\right)$, more than $8 \%$ SeaWiFS pixels had values at least twice as high as the MODISA $R_{\mathrm{rs}}$. In comparison, the high $R_{\mathrm{rs}}$ values in the IDAS-corrected data became much smaller than the original high $R_{\mathrm{rs}}$ values, as shown by the histograms in Figure 9 (Figures $9 \mathrm{~b}$ and $9 \mathrm{c}$ and Figures $9 \mathrm{e}$ and $9 \mathrm{f}$ ).

Figures $9 \mathrm{~g}$ and $9 \mathrm{~h}$ show the QAA and NQAA $b_{\mathrm{b}}(555)$ time series derived from the original SeaWiFS and MODISA Level- $2 R_{\mathrm{rs}}$ data. The QAA and NQAA $b_{\mathrm{b}}(555)$ time series were highly variable and the missions were inconsistent between the SeaWiFS and MODISA data (Figures $9 \mathrm{~g}$ and $9 \mathrm{~h}$ ). Due to the low-noise tolerance of the band ratio approach to residual errors, the QAA algorithm performed poorly in generating intermission consistent $b_{\mathrm{b}}(555)$ compared to the NQAA algorithm. For example, the annual mean MRV values were 1.83 and 1.42 for the QAA and NQAA algorithms, respectively. However, because REC in IDAS improves the consistency between the SeaWiFS and MODISA $R_{\mathrm{rs}}$ data, the IDAS-corrected intermission $b_{\mathrm{b}}(555)$ time series was more consistent than the $R_{\mathrm{rs}}$ data from the original time series (Figures $9 \mathrm{~h}$ to $9 \mathrm{j}$ ). Having the more consistent IDAS-corrected data meant that when we used IDAS-corrected $R_{\mathrm{rs}}$ data as inputs, the QAA algorithm compared favorably with the IDAS results (Figures 9i and 9j). The annual mean MRV and CV values for the IDAS results did not exceed 1.07 and 0.193 , respectively. From the results in Figures 10a to 10f, we concluded that IDAS largely reduced the intermission differences in $R_{\mathrm{rs}}$ data, which improved intermission consistency of the IOPs for the open ocean.

The original Level-2 $R_{\mathrm{rs}}$ data commonly include "high-quality" (HQ) and "low-quality" (LQ) data sets (Table 1), as defined by NASA staff and science teams (Hooker, 2003). To generate the global Level-3 composite ocean color data, a 32-bit value for each pixel (called "12_flags") separates the HQ pixels from the LQ pixels in Level-2 data. Figure 10 shows the histograms of LQ and HQ $R_{\mathrm{rs}}$ from the North Atlantic Gyre in 2009, before and after processing with IDAS. 

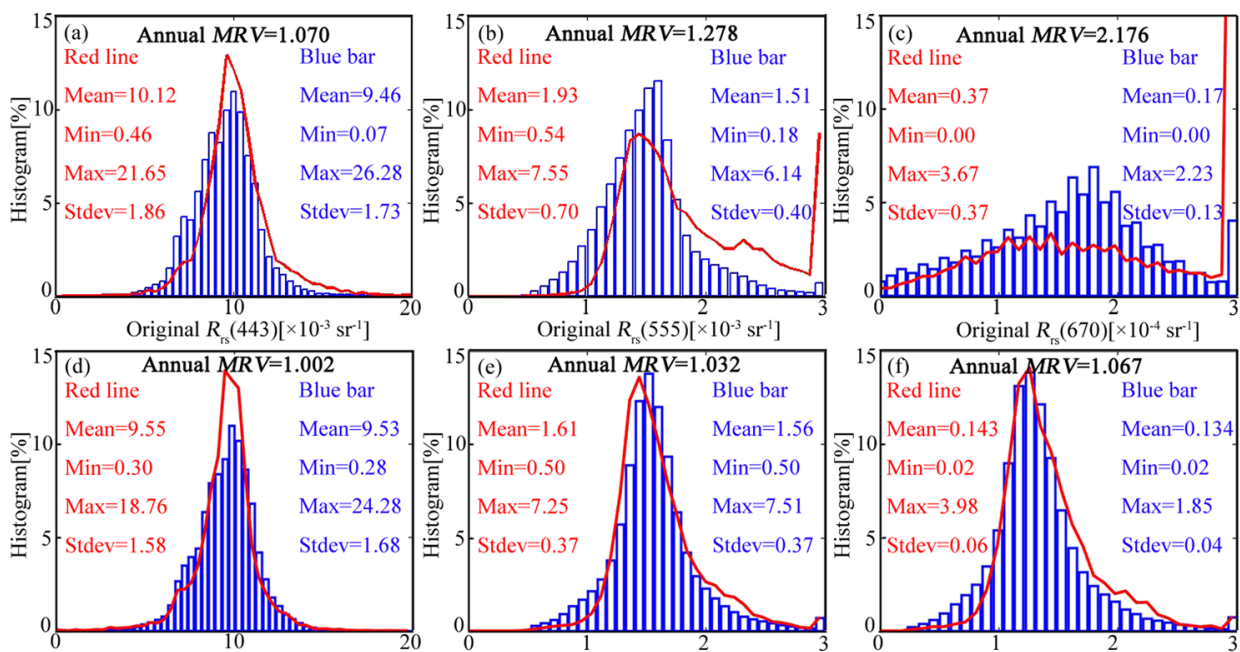

Original $R(670)\left[\times 10^{-4} \mathrm{sr}^{-1}\right]$

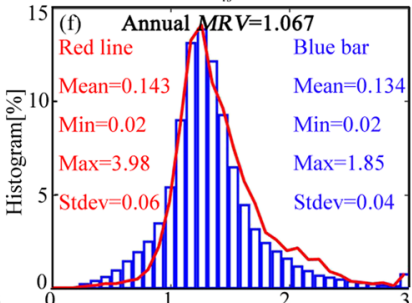

IDAS $R_{\mathrm{rs}}(443)\left[\times 10^{-3} \mathrm{sr}^{-1}\right]$

IDAS $R_{\mathrm{rs}}(555)\left[\times 10^{-3} \mathrm{sr}^{-1}\right]$

IDAS $R_{\mathrm{rs}}(670)\left[\times 10^{-4} \mathrm{sr}^{-1}\right]$
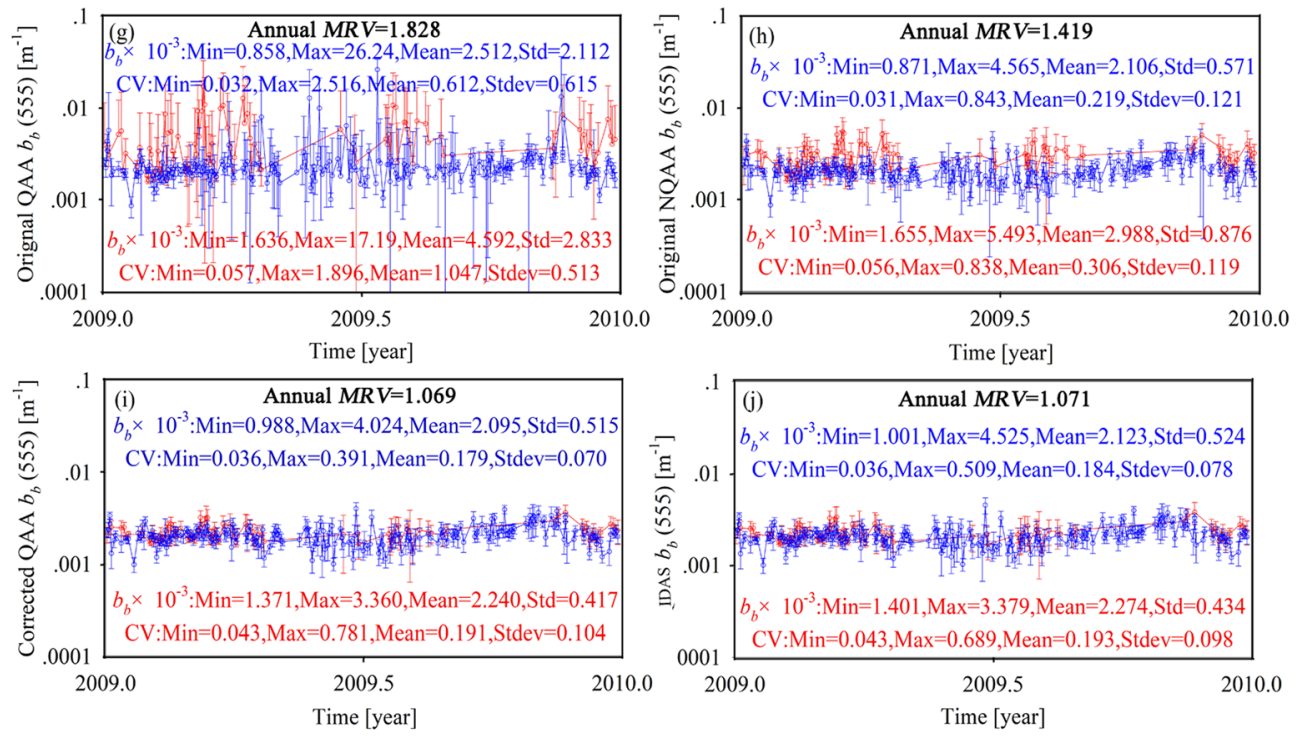

Figure 9. The IDAS and QAA algorithm-processed $R_{\mathrm{rs}}$ and $b_{\mathrm{b}}(555)$ over the North Atlantic Gyre $\left(24^{\circ}\right.$ to $26^{\circ} \mathrm{N}, 54^{\circ}$ to $\left.56^{\circ} \mathrm{W}\right)$ from 2009 . (a)-(c) are original $R_{\mathrm{rs}}$, while (d)-(f) are IDAS $R_{\mathrm{rs}}$; and $(\mathrm{g})$ and $(\mathrm{h})$ are QAA and IDAS daily $b_{\mathrm{b}}(555)$. The "red line" represents the results from SeaWiFS images $\left(n=1.3 \times 10^{6}\right)$, and the "blue bar" represents the results from MODISA images $\left(n=4.3 \times 10^{6}\right)$. The "circle" represents the daily mean $b_{\mathrm{b}}(555)$ calculated from all pixels in daily images within a $2^{\circ} \times$ $2^{\circ}$ square region, while the "vertical bar" denotes the mean deviation calculated from all pixels in daily images within a $2^{\circ} \times 2^{\circ}$ square region. The histograms were calculated from all pixels in the $2^{\circ} \times 2^{\circ}$ square region in all original or IDAS-corrected daily Level-2 data from 2009 .

Because backscattering coefficients at the green and red wavelengths in the open oceans are low, a small error in the $R_{\mathrm{rs}}(555)$ or $R_{\mathrm{rs}}(670)$ can greatly impact the blue to green and green to red band ratios. Because of these low backscattering coefficients (Figures 10a to 10d), the band-ratio QAA algorithm was sensitive to the intermission difference in the satellite $R_{\mathrm{rs}}$, which resulted in poor intermission consistency of $b_{\mathrm{b}}(555)$ derived from the LQ $R_{\mathrm{rs}}$ data. The annual MRV value of the LQ $R_{\mathrm{rs}}$ data for $b_{\mathrm{b}}(555)$ was 1.967. In comparison, the intermission consistency of $b_{\mathrm{b}}(555)$ derived from the HQ $R_{\mathrm{rs}}$ data was much higher than the intermission consistency of the LQ data, but the annual MRV value was 1.104. Because of the results from the original level- $2 R_{\mathrm{rs}}$ in Figure 9 (LQ data mixed with HQ data), we concluded that the LQ $R_{\mathrm{rs}}$ data were the main cause of the intermission inconsistency in the QAA $b_{\mathrm{b}}(555)$ products.

Because IDAS removes the intermission difference in $R_{\mathrm{rs}}$ data, IDAS works better than QAA in producing consistent intermission $b_{\mathrm{b}}(555)$ with LQ and HQ $R_{\mathrm{rs}}$ data (Figures 10i to 10p). Specifically, the annual MRV values for $b_{\mathrm{b}}(555)$ were 1.025 and 1.110, respectively, for the HQ and LQ $R_{\mathrm{rs}}$ data so that IDAS with LQ $R_{\mathrm{rs}}$ data had comparable intermission consistency to QAA with HQ $R_{\mathrm{rs}}$ data. Because $b_{\mathrm{b}}(555)$ can be 

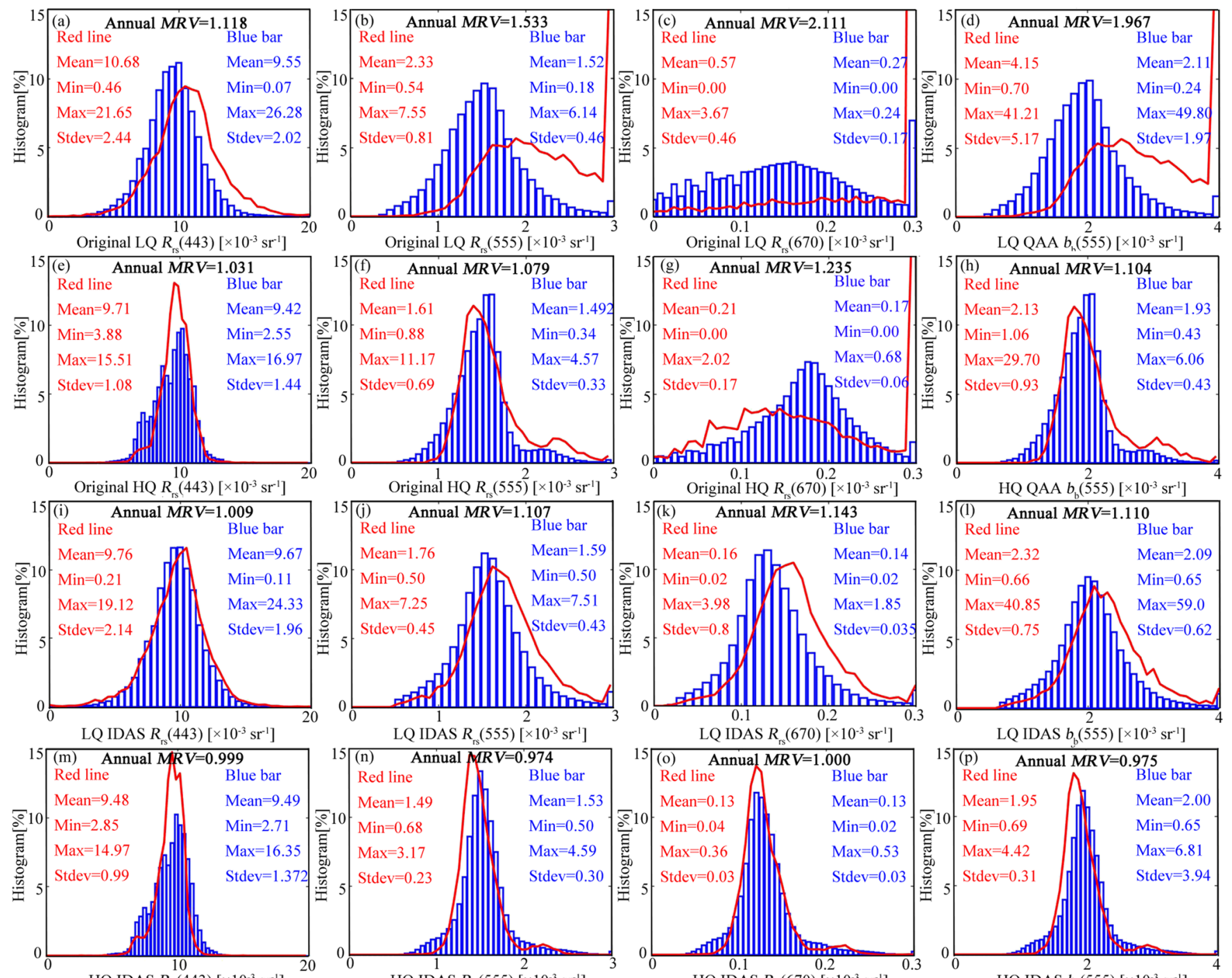

LQ IDAS $R_{\mathrm{rs}}(670)\left[\times 10^{-3} \mathrm{sr}^{-1}\right.$

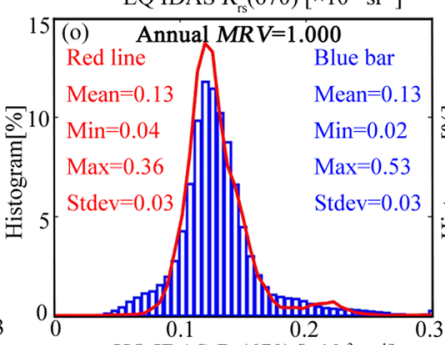

HQ IDAS $R_{r s}(670)\left[\times 10^{-3} \mathrm{sr}^{-1}\right]$
HQ QAA $b_{b}(555)\left[\times 10^{-3} \mathrm{sr}^{-1}\right]$

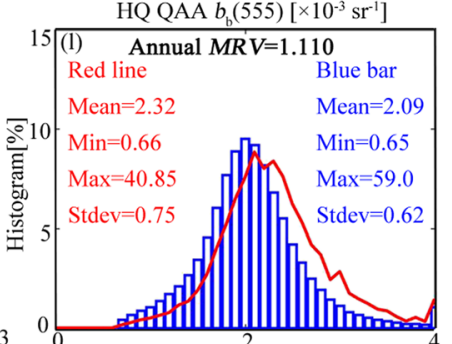

LQ IDAS $b_{\mathrm{b}}(555)\left[\times 10^{-3} \mathrm{sr}^{-1}\right]$

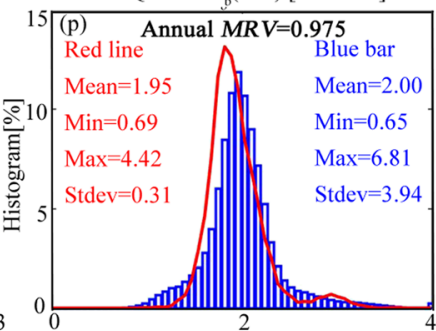

HQ IDAS $b_{\mathrm{b}}(555)\left[\times 10^{-3} \mathrm{sr}^{-1}\right]$

Figure 10. The IDAS and QAA algorithm-processed $b_{\mathrm{b}}(555)$ from LQ and HQ $R_{\mathrm{rs}}$ over a small region within the North Atlantic Gyre (24 $4^{\circ}$ to $26^{\circ} \mathrm{N}, 54^{\circ}$ to $\left.56^{\circ} \mathrm{W}\right)$ from 2009. (a)-(c) are original LQ $R_{\mathrm{rs}}$, while (e)-(g) are original HQ $R_{\mathrm{rs}}$; (d) and (h) are QAA $b_{\mathrm{b}}(555)$ derived from original LQ and HQ $R_{\mathrm{rs}}$ data; (i)-(k) are IDAS-corrected LQ $R_{\mathrm{rs}}$, while (m)-(o) are IDAS-corrected HQ $R_{\mathrm{rs}}$. (f) and (p) are IDAS $b_{\mathrm{b}}(555)$ derived from IDAS LQ and HQ $R_{\mathrm{rs}}$ data. The "red line" represents the results from SeaWiFS images $\left(n=6.1 \times 10^{5}\right.$ and $n=7.2 \times 10^{5}$, respectively, for HQ and LQ data), while the "blue bar" represents the results from MODISA images ( $n=1.9 \times 10^{6}$ and $n=2.4 \times 10^{6}$, respectively, for HQ and LQ data). All pixels with $R_{\mathrm{rs}}(\lambda)>0$ were analyzed. The histograms were calculated from all pixels in the $2^{\circ}$ $\times 2^{\circ}$ square region from all original or IDAS-corrected daily images from 2009. The 12_flags distinguished HQ pixels from LQ pixels.

converted to particle matter in these waters, the annual mean (within $\pm 2.5 \%$ ) intermission difference between SeaWiFS and MODISA $b_{\mathrm{b}}(555)$, derived from the HQ $R_{\mathrm{rs}}$ data, might be useful for detecting global interannual variability and analyzing particle matter concentration. We used the SeaWiFS and MODISA Level-2 data obtained over the South Pacific Gyre in 2009 to further demonstrate how capable IDAS was in generating intermission consistent $b_{\mathrm{b}}(555)$ for global blue water (Appendix B). The results were consistent with our results for the North Atlantic Gyre. Note that there are some cases, such as tracing eddies, where accuracy could be relaxed to allow for more data coverage (Hu, 2011) so that improving the quality of the LQ $R_{\mathrm{rs}}$ data could be very useful.

Figures 11a to 11d show the time series of SeaWiFS $b_{\mathrm{b}}(555)$ versus MODISA $b_{\mathrm{b}}(555)$ derived from the LQ and $\mathrm{HQ} R_{\mathrm{rs}}$ data for the North Atlantic Gyre using the IDAS and QAA algorithms. The IDAS and QAA algorithms produced $b_{\mathrm{b}}(555)$ from the $\mathrm{HQ} R_{\mathrm{rs}}$ data that made a more consistent intermission time series than 
Table 1

Symbols and Definitions

\begin{tabular}{|c|c|c|}
\hline Symbol & Description & Units \\
\hline$\lambda$ & Wavelength & $\mathrm{nm}$ \\
\hline$R_{\mathrm{rs}}(\lambda)$ & Remote sensing reflectance just above the water surface & $\mathrm{sr}^{-1}$ \\
\hline$R_{\mathrm{rs}, \mathrm{t}}(\lambda)$ & Error-free $R_{\mathrm{rs}}$ at algorithm wavelength system & $\mathrm{sr}^{-1}$ \\
\hline$\triangle R_{\mathrm{rs}, \mathrm{r}}(\lambda)$ & Residual error in satellite $R_{\mathrm{rs}}(\lambda)$ & $\mathrm{sr}^{-1}$ \\
\hline$\triangle R_{\mathrm{rs}, \mathrm{b}}(\lambda)$ & Intermission bias between true satellite $R_{\mathrm{rs}}$ & $\mathrm{sr}^{-1}$ \\
\hline$\triangle R_{\mathrm{rs}, \mathrm{d}}(\lambda)$ & Intermission difference between satellite $R_{\mathrm{rs}}$ & $\mathrm{sr}^{-1}$ \\
\hline$a(\lambda)$ & Total absorption coefficient & $\mathrm{m}^{-1}$ \\
\hline$b_{\mathrm{bp}}(\lambda)$ & Backscattering coefficient of suspended particles & $\mathrm{m}^{-1}$ \\
\hline$b_{\mathrm{b}}(\lambda)$ & Total backscattering coefficient & $\mathrm{m}^{-1}$ \\
\hline POC & Particulate organic carbon & $\mu \mathrm{g} / \mathrm{kg}$ \\
\hline MAPD & Mean absolute percent difference & $\%$ \\
\hline MRV & Mean ratio value & Dimensionless \\
\hline$Y$ & Power coefficient of $b_{\mathrm{bp}}(\lambda)$ & Dimensionless \\
\hline$S\left(\lambda_{\mathrm{i}}, \lambda_{\mathrm{j}}\right)$ & Slope of linear relationship of $\triangle R_{\mathrm{rs}}(\lambda)$ between $\lambda_{\mathrm{i}}$ and $\lambda_{\mathrm{j}}$ & Dimensionless \\
\hline$B\left(\lambda_{\mathrm{i}}, \lambda_{\mathrm{j}}\right)$ & Bias of linear relationship of $\triangle R_{\mathrm{rs}}(\lambda)$ between $\lambda_{\mathrm{i}}$ and $\lambda_{\mathrm{j}}$ & Dimensionless \\
\hline$S_{\mathrm{dg}}$ & Spectral slope of sum absorption of detritus and gelbstoff & Dimensionless \\
\hline $\mathrm{RMSE}_{\log }$ & Root-mean-square of log transformed difference & Dimensionless \\
\hline $\mathrm{CV}$ & Coefficient of variation & Dimensionless \\
\hline STD & Standard deviation & Vary with inputs \\
\hline IOPs & Inherent optical properties & $\mathrm{N} / \mathrm{A}$ \\
\hline IDAS & IOPs data processing system & $\mathrm{N} / \mathrm{A}$ \\
\hline QAA & Quasi-analytical algorithm & N/A \\
\hline NQAA & Neural network-based quasi-analytical algorithm & N/A \\
\hline REC & Residual error correction algorithm & $\mathrm{N} / \mathrm{A}$ \\
\hline SeaWiFS & Sea-viewing Wide Field-of-view Sensor & $\mathrm{N} / \mathrm{A}$ \\
\hline SeaBASS & SeaWiFS Bio-optical Archive and Storage System & $\mathrm{N} / \mathrm{A}$ \\
\hline NASA & National Aeronautics and Space Administration & $\mathrm{N} / \mathrm{A}$ \\
\hline AERONET & Aerosol Robotic Network & N/A \\
\hline SIMBIOS & Biological and Interdisciplinary Oceanic Studies & N/A \\
\hline Low quality (LQ) & \multicolumn{2}{|c|}{ Level-2 data associated with one or more 12_flags but still within the application boundaries defined in this study } \\
\hline High quality (HQ) & \multicolumn{2}{|c|}{ Level-2 data not associated with any 12_flags but still within the application boundaries defined in this study } \\
\hline 12_flags & \multicolumn{2}{|c|}{$\begin{array}{l}\text { ATMFAIL (1), LAND (2), HIGLINT (4), HILT (5), HISATZEN (6), STRAYLIGHT (9), CLDICE (10), HISOLZEN (13), LOWLW (15), } \\
\text { CHLFAIL (16), NAVWARN (17), MAXAERITER (20), CHLWARN (22), ATMWARN (23), NAVFAIL (26), and FILTER (27) }\end{array}$} \\
\hline
\end{tabular}

what they produced from the LQ $R_{\mathrm{rs}}$ data. For the QAA algorithm, the annual MRV values were 2.353 and 1.177, respectively, for the LQ and HQ $R_{\mathrm{rs}}$ data. However, after applying IDAS to the same data set, the annual MRV values for the LQ and HQ $R_{\mathrm{rs}}$ data decreased to 1.170 and 1.015 , respectively. This signifies that IDAS with LQ $R_{\mathrm{rs}}$ data had an intermission consistent time series comparable to the QAA time series with HQ $R_{\mathrm{rs}}$ data.

All our results in this section confirmed that the intermission biases for $R_{\mathrm{rs}}$ at the visible wavelengths had the same sign (equations (16) to (17)), and only the intermission biases at visible wavelengths had the same sign. So IDAS works at absorbing intermission bias for residual error computation, or the intermission biases cannot be removed using IDAS, which makes IDAS effective in generating the intermission consistent $b_{\mathrm{b}}(555)$ for detecting interannual variability

Table 2

Ranges of Optical Properties of the In Situ NOMAD Data Set Used to Test IDAS, Including $R_{r s}(\lambda)-b_{b}(555)$ Sample Pairs Measured From 473 Stations and $R_{r s}(\lambda)-a(443)$ Sample Pairs Measured From 1,132 Stations

\begin{tabular}{lcccccc}
\hline Data set & Variable & Min & Max & Median & Average & STD \\
\hline NOMAD data & $a_{\mathrm{ph}}(443)$ & 0.002 & 1.480 & 0.174 & 0.119 & 0.047 \\
set, $n=954$ & $a_{\mathrm{dg}}(443)$ & 0.003 & 1.802 & 0.283 & 0.203 & 0.064 \\
& $b_{\mathrm{b}}(555)$ & 0.001 & 0.009 & 0.003 & 0.004 & 0.002 \\
& $S_{\mathrm{dg}}$ & 0.005 & 0.034 & 0.014 & 0.014 & 0.001 \\
& $Y$ & -0.785 & 2.378 & 0.637 & 0.644 & 0.481 \\
\hline
\end{tabular}
and analyzing the global blue ocean.

3.3.4. Assessing the Individual Component Absorption Retrievals It is difficult to use one spectral relationship to describe the spectral dependent characteristics of residual error and intermission bias in $R_{\mathrm{rs}}$ (Figure 3). So the $\triangle R_{\mathrm{rs}}(670)$ cannot completely reduce the intermission bias in $R_{\mathrm{rs}}$ for retrieving $b_{\mathrm{b}}(555)$. Because it is possible to accurately determine the $a(555)$ and $Y$, the $R_{\mathrm{rs}}(555)$ error propagates to $b_{\mathrm{b}}(555)$ (Chen et al., 2016; Lee et al., 2002) when $b_{\mathrm{b}}(555)$ is retrieved based on the $R_{\mathrm{rs}}$ IOPs relationship that Gordon et al. (1988) proposed. Because we extrapolated $b_{\mathrm{b}}(\lambda)$ from $b_{\mathrm{b}}(555)$ in IDAS, after applying a spectral model of the 

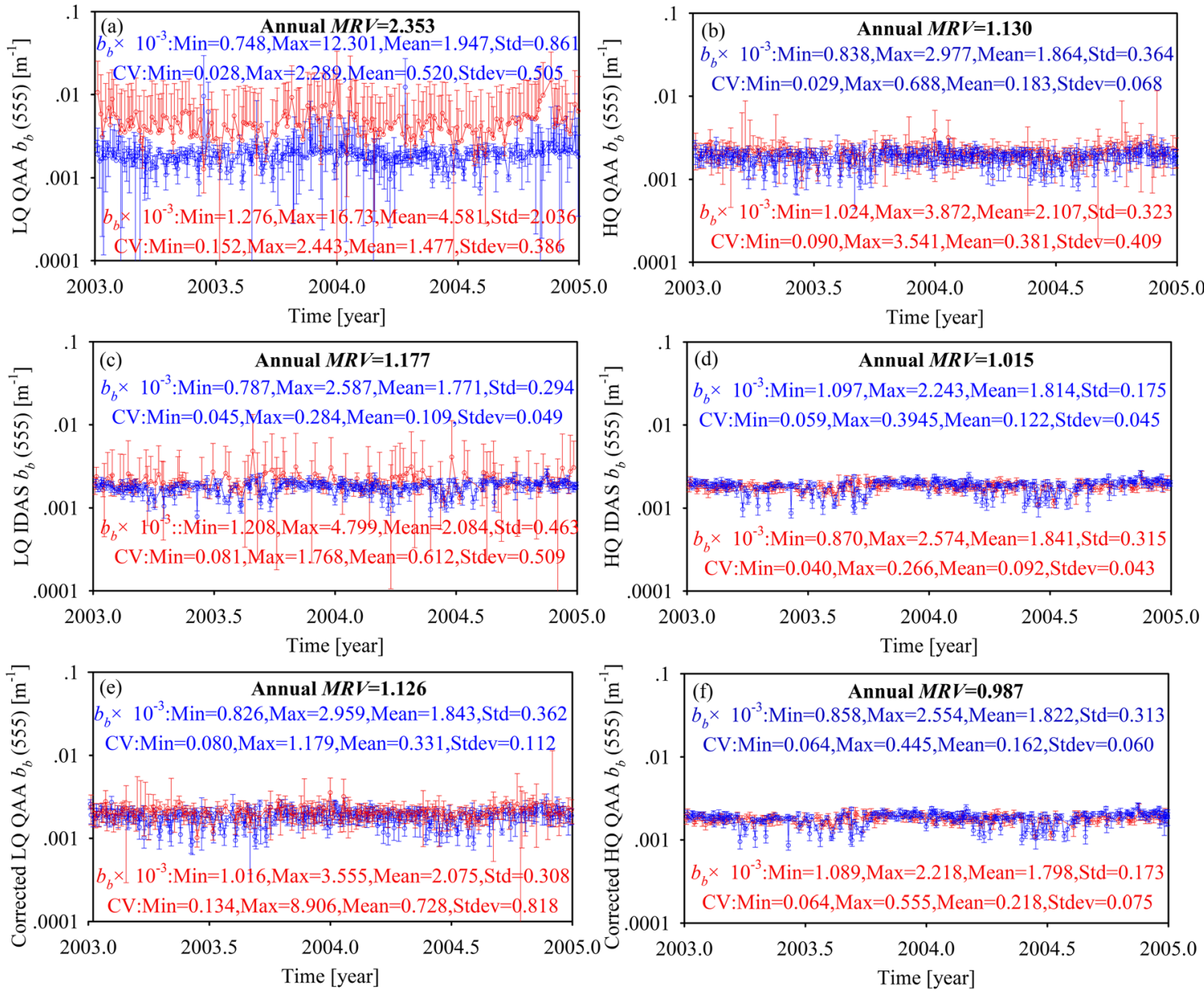

Figure 11. Daily $b_{b}(555)$ retrieved from LQ and HQ SeaWiFS and MODISA Level-2 images over a small region within the North Atlantic Gyre $\left(24^{\circ}\right.$ to $26^{\circ} \mathrm{N}, 54^{\circ}$ to $56^{\circ} \mathrm{W}$ ) from 2003 to 2004. (a) and (b) are LQ and HQ QAA $b_{b}(555)$ retrieved from the original $R_{\mathrm{rs}}$ data. (c) and (d) are IDAS LQ and HQ $b_{b}(555)$. (e) and (f) are LQ and HQ QAA $b_{b}(555)$ retrieved from IDAS-corrected $R_{\mathrm{rs}}$ data. The "red line" represents the results from SeaWiFS images $\left(n=3.8 \times 10^{6}\right.$ and $n=4.7 \times 10^{6}$, respectively, for HQ and LQ data), while the "blue line" represents the results from MODISA images ( $n=1.3 \times 10^{7}$ and $n=1.8 \times 10^{7}$, respectively, for HQ and LQ data). All pixels with $R_{\mathrm{rs}}(\lambda)>0$ were analyzed. The "red line" represents the SeaWiFS data, while the "blue bar" represents the MODISA data. The "circle" represents the daily mean $b_{\mathrm{b}}(555)$ calculated from all pixels in daily images within a $2^{\circ} \times 2^{\circ}$ square region, while the "vertical bar" denotes the mean deviation calculated from all pixels in daily images within the $2^{\circ} \times 2^{\circ}$ square region. The 12_flags distinguished HQ pixels from LQ pixels.

particle backscattering coefficient (Garver \& Siegel, 1997; IOCCG, 2006; Lee et al., 2002), there will be some compensation between $b_{\mathrm{b}}(\lambda)$ and $u(\lambda)$ for $a(\lambda)$.

Figure 12 compares SeaWiFS a(443) with MODISA $a(443)$ derived from LQ and HQ $R_{\mathrm{rs}}$ data in the Level-2 images of the North Atlantic Gyre and South Pacific Gyre from 2009. Because QAA performed poorly in quantifying the intermission consistent $b_{\mathrm{b}}(\lambda)$ at the reference wavelength, there were some clear intermission differences from the QAA $a(443)$ (Figures 12a to 12d). For the HQ $R_{\text {rs }}$ data (Figures 12a and 12c), the annual MRV values for $a(443)$ were 1.068 and 1.051, respectively, for the North Atlantic Gyre and South Pacific Gyre. Contrary to the QAA result, IDAS with LQ $R_{\mathrm{rs}}$ data produced intermission consistent $a(443)$ (Figures $12 \mathrm{f}$ and $12 \mathrm{~h}$ ) comparable to what QAA produced from the HQ $R_{\mathrm{rs}}$ data. For the HQ $R_{\mathrm{rs}}$ data, the annual MRV values for $a(443)$ were very close to 1 (equal to 0.988) for the North Atlantic Gyre and South Pacific Gyre (Figures 12e and 12g). We attributed these significant improvements to the strong performance of IDAS in generating the high intermission consistent $b_{\mathrm{b}}(555)$ time series for blue water (within $\pm 3 \%$ annual MRV).

When we determine the $a(\lambda)$ at blue wavelengths with high intermission consistency, we can obtain the component individual absorption from $a(\lambda)$ with high intermission consistency for the open ocean (Lee 

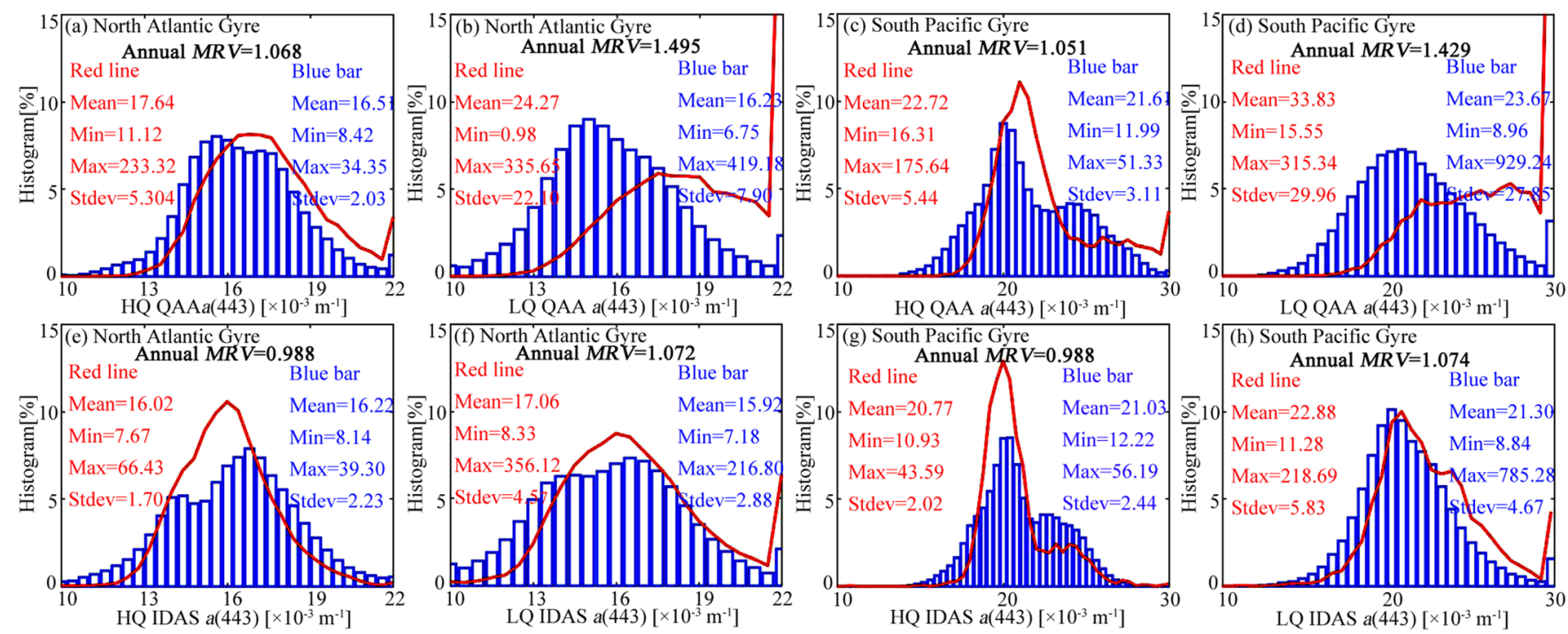

Figure 12. Histograms of daily $a(443)$ over a small region within the North Atlantic Gyre $\left(24^{\circ}\right.$ to $26^{\circ} \mathrm{N}, 54^{\circ}$ to $\left.56^{\circ} \mathrm{W}\right)$ and South Pacific Gyre $\left(34^{\circ}\right.$ to $36^{\circ} \mathrm{S}$, $114^{\circ}$ to $116^{\circ} \mathrm{W}$ ) from 2009. (a) and (c) are HQ QAA $a(443)$ from the North Atlantic Gyre and South Pacific Gyre, while (b) and (d) are LQ QAA $a(443)$ from the North Atlantic Gyre and South Pacific Gyre; (e) and (g) are HQ IDAS a(443) from the North Atlantic Gyre and South Pacific Gyre, while (f) and (h) are LQ IDAS a(443) from the North Atlantic Gyre and South Pacific Gyre. The "red line" represents the results from SeaWiFS images $\left(n=6.1 \times 10^{5}\right.$ and $n=7.2 \times 10^{5}$, respectively, for HQ and LQ data in the North Atlantic Gyre and $n=2.5 \times 10^{6}$ and $n=2.5 \times 10^{6}$, respectively, for HQ and LQ data in the South Pacific Gyre), while the "blue bar" represents the results from MODISA images $\left(n=1.9 \times 10^{6}\right.$ and $n=2.4 \times 10^{6}$, respectively, for HQ and LQ data in the North Atlantic Gyre and $n=6.9 \times 10^{6}$ and $n=$ $8.6 \times 10^{6}$, respectively, for HQ and LQ data in the South Pacific Gyre). All pixels with $R_{\mathrm{rs}}(\lambda)>0$ were analyzed. The histograms were calculated from all pixels in the $2^{\circ} \times 2^{\circ}$ square region in all original or IDAS-corrected daily images from 2009. The 12_flags distinguished HQ pixels from LQ pixels.

et al., 2002; Werdell et al., 2013). We used the SeaWiFS and MODISA Level-2 $R_{\mathrm{rs}}$ data from the North Atlantic Gyre and South Pacific Gyre to run the IDAS and QAA algorithms to retrieve $a_{\mathrm{g}}(443)$ and $a_{\mathrm{ph}}(443)$. The detritus absorption coefficients are very low in the open ocean (Mobley, 1994); thus, we used $a_{\mathrm{g}}(443)$ to represent the nonphytoplankton absorption coefficients in this study. Due to its strong performance in generating intermission consistent $a(\lambda)$ products, IDAS performed far better than the QAA algorithm in retrieving intermission consistent $a_{\mathrm{g}}(443)$ and $a_{\mathrm{ph}}(443)$ products for blue water (Figure 13).

The QAA algorithm with HQ $R_{\mathrm{rs}}$ data produced more intermission consistent $a_{\mathrm{g}}(443)$ and $a_{\mathrm{ph}}(443)$ than with $\mathrm{LQ} R_{\mathrm{rs}}$ data, and the corresponding annual MRV values varied from 1.027 to 1.280. This meant that the QAA component individual absorptions retrieved from SeaWiFS data were $2.7 \%$ to $28.0 \%$ larger than those from MODISA for blue water. Overall, the intermission consistency for QAA $a_{\mathrm{g}}(443)$ was much better than the QAA $a_{\mathrm{ph}}(443)$. For example, the annual MRV values were less than 1.054 for the former but more than 1.166 for the latter. It seems that most intermission differences in $a(\lambda)$ propagated to $a_{\mathrm{ph}}(443)$ products as opposed to $a_{\mathrm{g}}(443)$ (Figures 12,13). In fact, the QAA $a_{\mathrm{ph}}(443)$ values were much lower than the QAA $a_{\mathrm{g}}(443)$, so the QAA $a_{\mathrm{ph}}(443)$ were more sensitive to the uncertainty in $a(\lambda)$ than the QAA $a_{\mathrm{g}}(443)$.

Like the QAA algorithm, IDAS worked significantly better with $\mathrm{HQ} R_{\mathrm{rs}}$ data than with $\mathrm{LQ} R_{\mathrm{rs}}$ data, but the annual MRV values for $a_{\mathrm{g}}(443)$ and $a_{\mathrm{ph}}(443)$ were clearly closer to 1.0 than the MRVs of the QAA algorithm. Specifically, the annual MRV values for the component individual absorption varied from 0.971 to 0.981 . In other words, using IDAS resulted in an annual intermission difference for $a_{\mathrm{g}}(443)$ and $a_{\mathrm{ph}}(443)$ within only $\pm 2.91 \%$, which was significantly lower than the difference observed for the QAA algorithm.

Because of the effects originating from the intermission difference, we found many poor points (negative values) in the QAA IOPs results (Figures 13b, 13d, and 13k). We removed the negative values for $a_{\mathrm{ph}}(443)$ and $a_{\mathrm{g}}(443)$ because they were not appropriate for the analysis, which lead to decreasing data coverage of the open ocean. After processing the images with the IDAS algorithm, the number of invalid points decreased significantly. Compared to the QAA results, the new IOPs data from the IDAS algorithm were more tightly distributed, and the standard deviations decreased. These results indicate that IDAS improved the IOPs quality for blue water. 


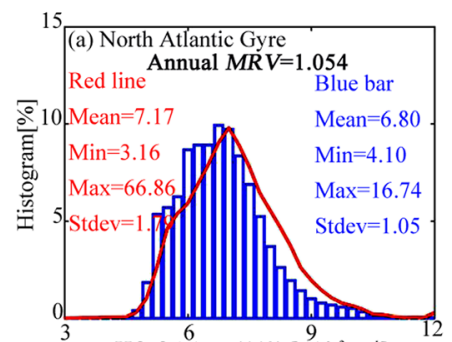

HQ QAA $a_{\mathrm{dg}}(443)\left[\times 10^{-3} \mathrm{~m}^{-1}\right]$
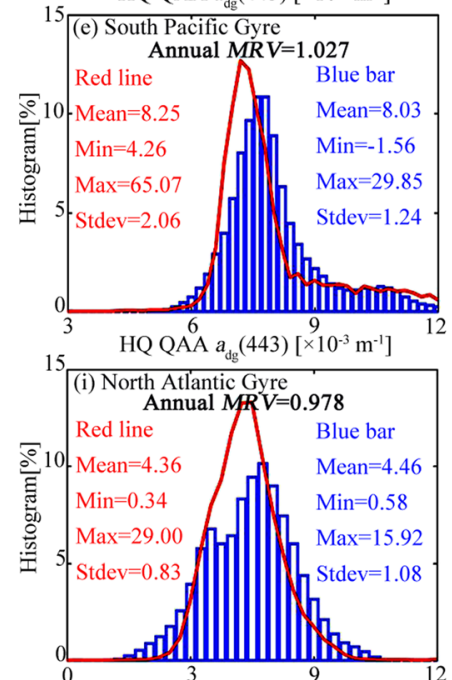

HQ IDÀs $a_{g}(443)\left[\stackrel{9}{9} \times 10^{-3} \mathrm{~m}^{-1}\right]$

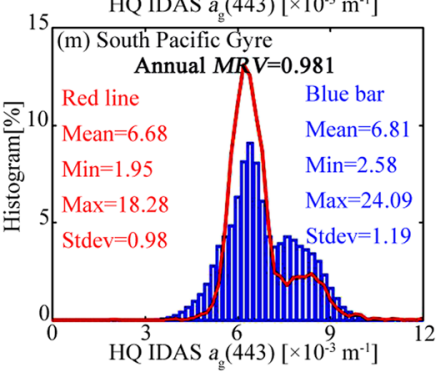

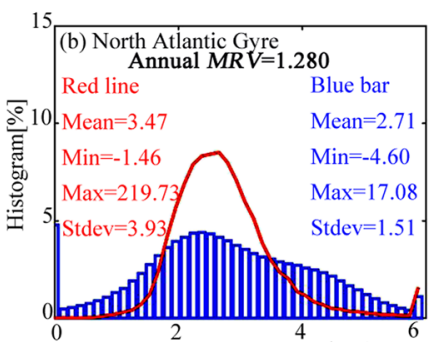

HQ QAA $a_{p h}(443)\left[\times 10^{-3} \mathrm{~m}^{-1}\right]$
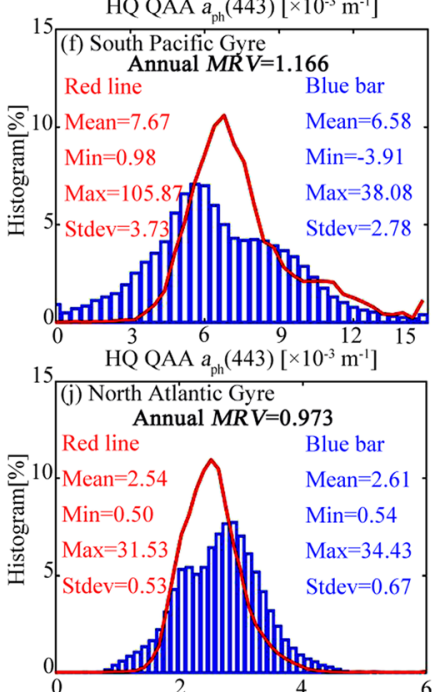

HQ IDÅ $\stackrel{2}{a_{\mathrm{ph}}}(443)\left[\stackrel{4}{4} 0^{-3} \mathrm{~m}^{-1}\right]$

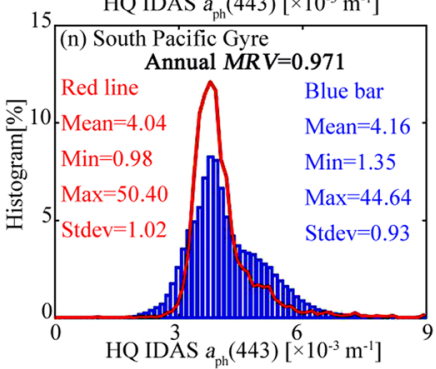

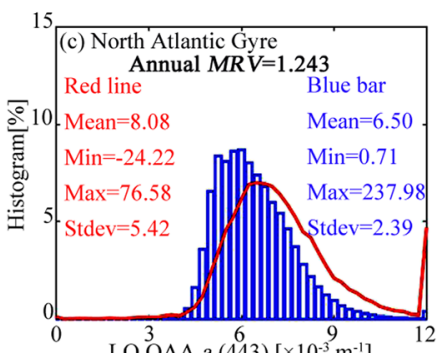

LQ $\stackrel{3}{Q}$ AA $a_{\mathrm{g}}(\stackrel{6}{4} 3)\left[\times 10^{-3} \mathrm{~m}^{-1}\right]$
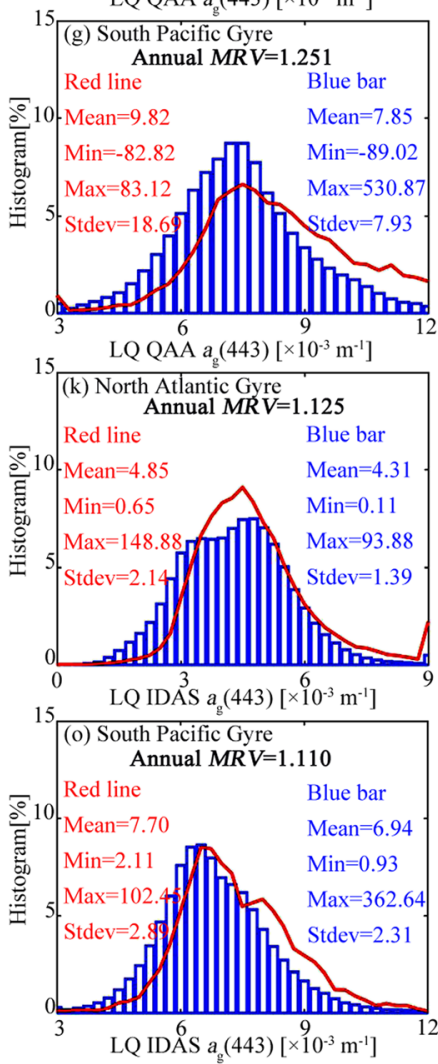

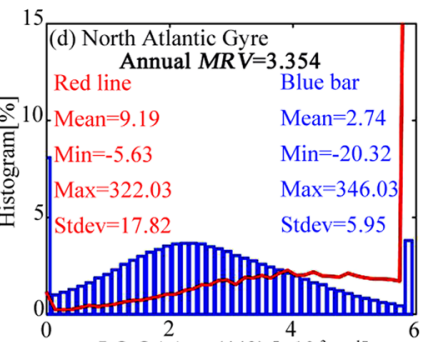

LQ QAA $a_{10}(443)\left[\times 10^{-3} \mathrm{~m}^{-1}\right]$
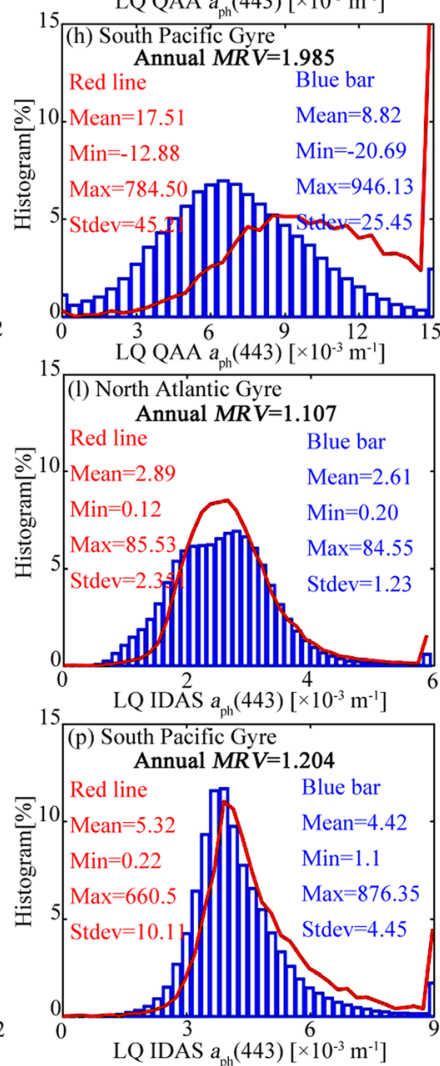

Figure 13. Histograms of daily $a_{\mathrm{g}}(443)$ and $a_{\mathrm{ph}}(443)$ over a small region within the North Atlantic Gyre $\left(24^{\circ}\right.$ to $26^{\circ} \mathrm{N}, 54^{\circ}$ to $\left.56^{\circ} \mathrm{W}\right)$ and South Pacific Gyre ( $34^{\circ}$ to $36^{\circ} \mathrm{S}, 114^{\circ}$ to $116^{\circ} \mathrm{W}$ ) in 2009. (a)-(d) and (e)-(h) are QAA and IDAS results from the North Atlantic Gyre, while (i)-(l) and (m)-(p) are QAA and IDAS results from the South Pacific Gyre. The "red line" represents the results from SeaWiFS images $\left(n=6.1 \times 10^{5}\right.$ and $n=7.2 \times 10^{5}$, respectively, for HQ and LQ data in the North Atlantic Gyre and $n=2.5 \times 10^{6}$ and $n=2.5 \times 10^{6}$, respectively, for HQ and LQ data in the South Pacific Gyre), while the "blue bar" represents the results from MODISA images $\left(n=1.9 \times 10^{6}\right.$ and $n=2.4 \times 10^{6}$, respectively, for HQ and LQ data in the North Atlantic Gyre and $n=6.9 \times 10^{6}$ and $n=8.6 \times 10^{6}$, respectively, for HQ and LQ data in the South Pacific Gyre). All pixels with $R_{\mathrm{rs}}(\lambda)>0$ were analyzed. The histograms were calculated from all pixels in the $2^{\circ} \times 2^{\circ}$ square region in all original or IDAS-corrected daily images from 2009. The 12_flags distinguished HQ pixels from LQ pixels.

\section{Discussion}

\subsection{Comparing Gain Factor Calibration Results}

In the past, methods for removing the intermission difference have focused on the intermission consistency of chlorophyll-a concentration (Gregg et al., 2009; Kahru et al., 2015; Mélin et al., 2017; Pottier et al., 2006; Saulquin et al., 2013). One of these methods is the empirical gain factor cross-calibration approach, which reduces the deviation between two measurements (Eplee et al., 2011; Mélin et al., 2017; Quan, 2014; Teillet et al., 2007). The empirical gain factor approach is similar to the empirical satellite-to-satellite approach that Kahru et al. (2015) proposed. To further examine how well IDAS performs in generating intermission consistent IOPs for the global open ocean, we determined the gain factors from the North Atlantic Ocean and then applied them to minimize the intermission difference for IOPs retrievals. Note that the satellite-to-satellite 

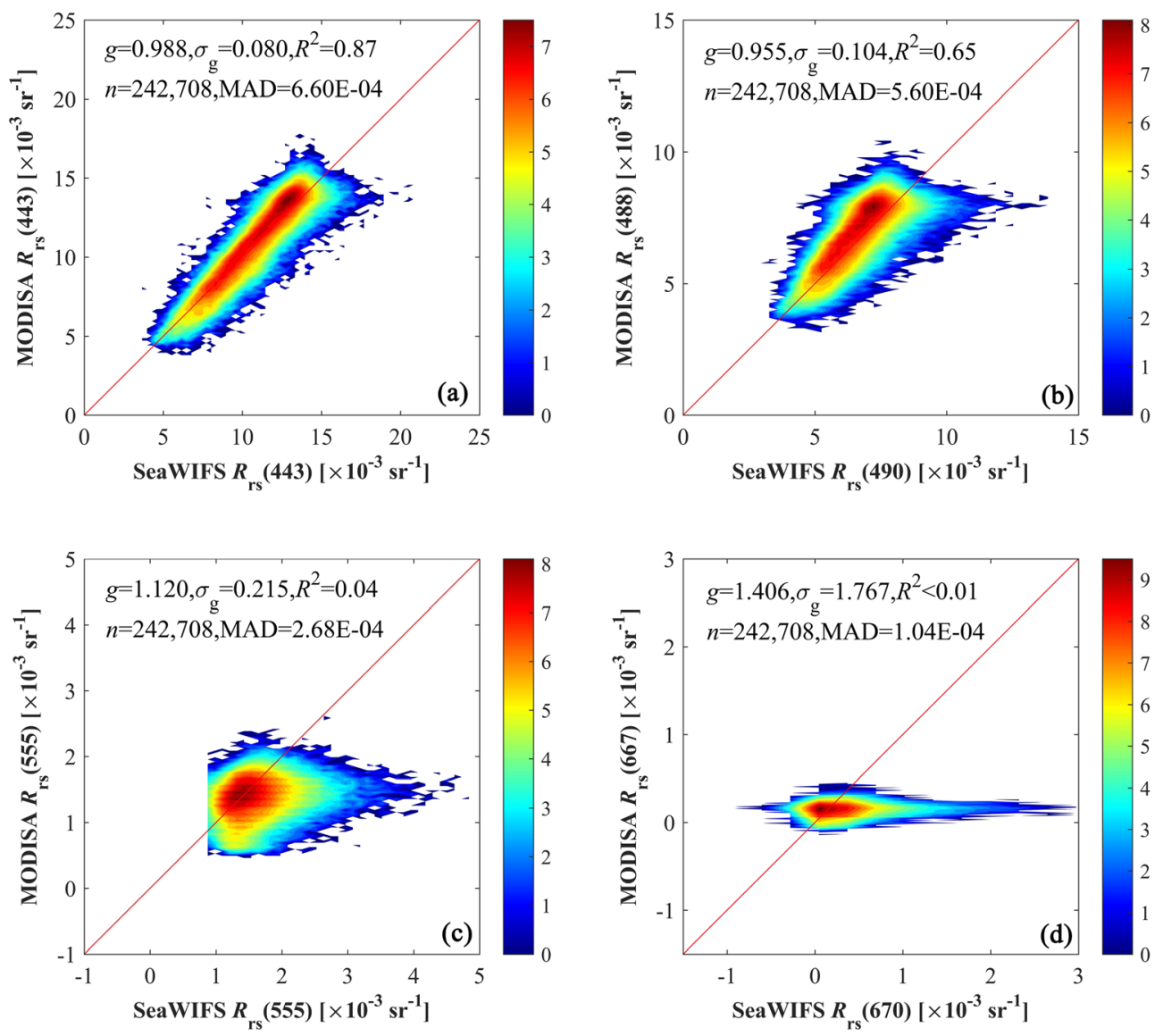

Figure 14. The gain factor cross-calibration algorithm for MODISA $R_{\mathrm{rs}}$ versus the same for SeaWiFS $R_{\mathrm{rs}}$ at (a) 443 , (b) 490 , (c) 555 , and (d) $667 \mathrm{~nm}$ regressed from 365 daily Level-3 SeaWiFS and MODISA $R_{\mathrm{rs}}$ images of the North Atlantic Gyre $\left(20^{\circ}\right.$ to $30^{\circ} \mathrm{N}, 50^{\circ}$ to $60^{\circ} \mathrm{W}$ ) from 2006 .

$R_{\mathrm{rs}}$ relationship at $670 \mathrm{~nm}$ was very poor, so, instead, we used the gain factor approach to correct the intermission difference.

Figure 14 shows the gain factors calculated from the global 9-km climatological daily images of the North Atlantic Gyre in 2009 (Level-3 data that were masked by 12_flags suggested by Hooker et al., 2001). The SeaWiFS $R_{\mathrm{rs}}$ differed from the MODISA $R_{\mathrm{rs}}$ for the open ocean, which was consistent with the results in Figure 2. For example, the SeaWiFS $R_{\mathrm{rs}}$ were slightly smaller than the MODISA $R_{\mathrm{rs}}$ at blue wavelengths, but the former were significantly larger than the latter at the green and red wavelengths. The coefficients of determination $\left(R^{2}\right)$ of the linear relationship between MODISA and SeaWiFS $R_{\mathrm{rs}}$ were very small at 555 and $670 \mathrm{~nm}\left(R^{2}<0.1\right)$ because the $R_{\mathrm{rs}}$ values at those wavelengths were low and comparable to the residual error (Chen et al., 2016). The gain factors reached 1.120 and 1.406 at 555 and $670 \mathrm{~nm}$, respectively.

We used the gain factors to minimize the intermission difference in the HQ Level-2 $R_{\mathrm{rs}}$ data between the SeaWiFS and MODISA images of the North Atlantic Gyre and South Pacific Gyre. Figure 15 compares the SeaWiFS IOPs with MODISA IOPs that we derived using the IDAS and QAA algorithms with the HQ $R_{\mathrm{rs}}$ data corrected with the gain factors. Compared with the results we derived from the original HQ $R_{\mathrm{rs}}$ data (Figures 9-13), the gain factor approach reduced some intermission difference for the IOPs retrieved with the QAA algorithm for the South Pacific Gyre data (Figures 15a to 15d), but the performance was better for the North Atlantic Gyre data (Figures 15e to 15h). When we applied the gain factors to the HQ Level-2 $R_{\mathrm{rs}}$ data, the spectral characteristics of remote sensing reflectance and residual errors changed, which negatively influenced IDAS in consistently retrieving intermission IOPs (Figures 15i to 15p). 

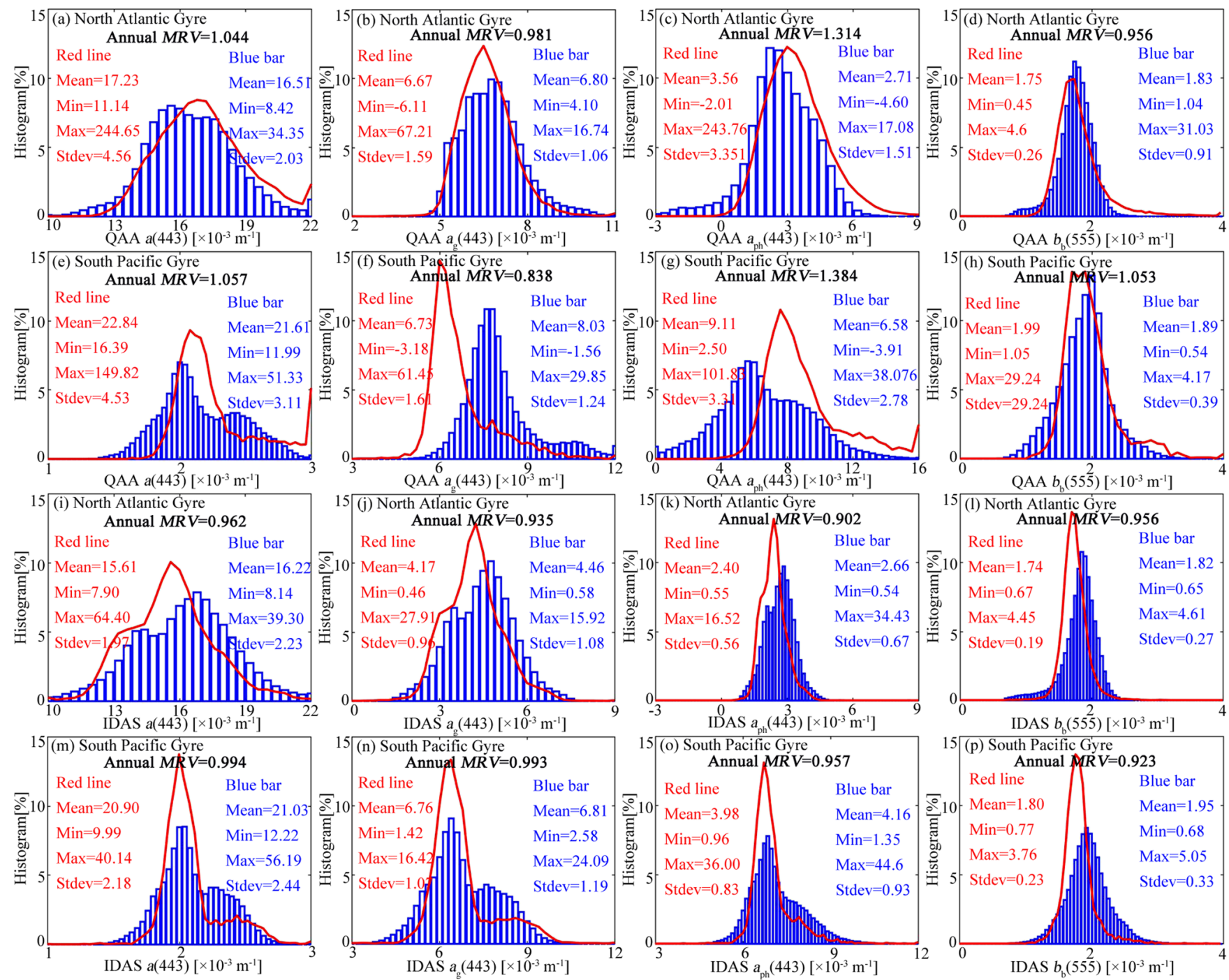

Figure 15. Histograms of the empirical gain factor cross-calibration approach corrected daily IOPs over a small region within the North Atlantic Gyre $\left(24^{\circ}\right.$ to $26^{\circ} \mathrm{N}$, $54^{\circ}$ to $56^{\circ} \mathrm{W}$ ) and South Pacific Gyre ( $34^{\circ}$ to $36^{\circ} \mathrm{S}, 114^{\circ}$ to $116^{\circ} \mathrm{W}$ ) from 2009. (a)-(d) and (i)-(l) are QAA and IDAS results from North Atlantic Gyre, while (e)-(h) and (m)-(p) are QAA and IDAS results from South Pacific Gyre. All HQ pixels with $R_{\mathrm{rs}}(\lambda)>0$ were analyzed. The histograms were calculated from all pixels in the $2^{\circ} \times 2^{\circ}$ square region in all original or IDAS-corrected daily images in 2009. The "red line" represents the results from SeaWiFS images, while the "blue bar" represents the results from MODISA images. The 12_flags distinguished HQ pixels from LQ pixels.

Many factors lead to the residual errors in the satellite Level-2 $R_{\mathrm{rs}}$ data, including digitization noise, atmospheric corrections, whitecap corrections, and cloudy neighborhood effects. In the open ocean, the water bodies are very homogeneous and stable at large spatial and temporal scales, especially in the South Pacific Gyre and North Atlantic Gyre (Chen et al., 2016; Hu et al., 2013). When the data quality is ideally controlled by 12_flags, the residual error in the satellite $R_{\mathrm{rs}}$ data is very small and the intermission $R_{\mathrm{rs}}$ might be strongly related with each other because of similar oceanic and atmospheric conditions and different spectral responses in the sensors. However, the actual intermission relationships for $R_{\mathrm{rs}}$ are more complicated than the ideal scenario. Therefore, there were systematic differences (SeaWiFS $R_{\mathrm{rs}}$ was statistically larger than MODISA $R_{\mathrm{rs}}$ ) among most of the intermission $R_{\mathrm{rs}}$ data in Figure 10, and there were large variations around the average difference between the SeaWiFS and MODISA $R_{\mathrm{rs}}$ (Figure 14). These different residual error and intermission bias characteristics eliminated the applicability of the gain factor approach for correcting intermission consistency of $R_{\mathrm{rs}}$ for the open ocean. The results showed that the IDAS algorithm worked more effectively than the gain factor approach in obtaining the intermission consistent $R_{\mathrm{rs}}$. 

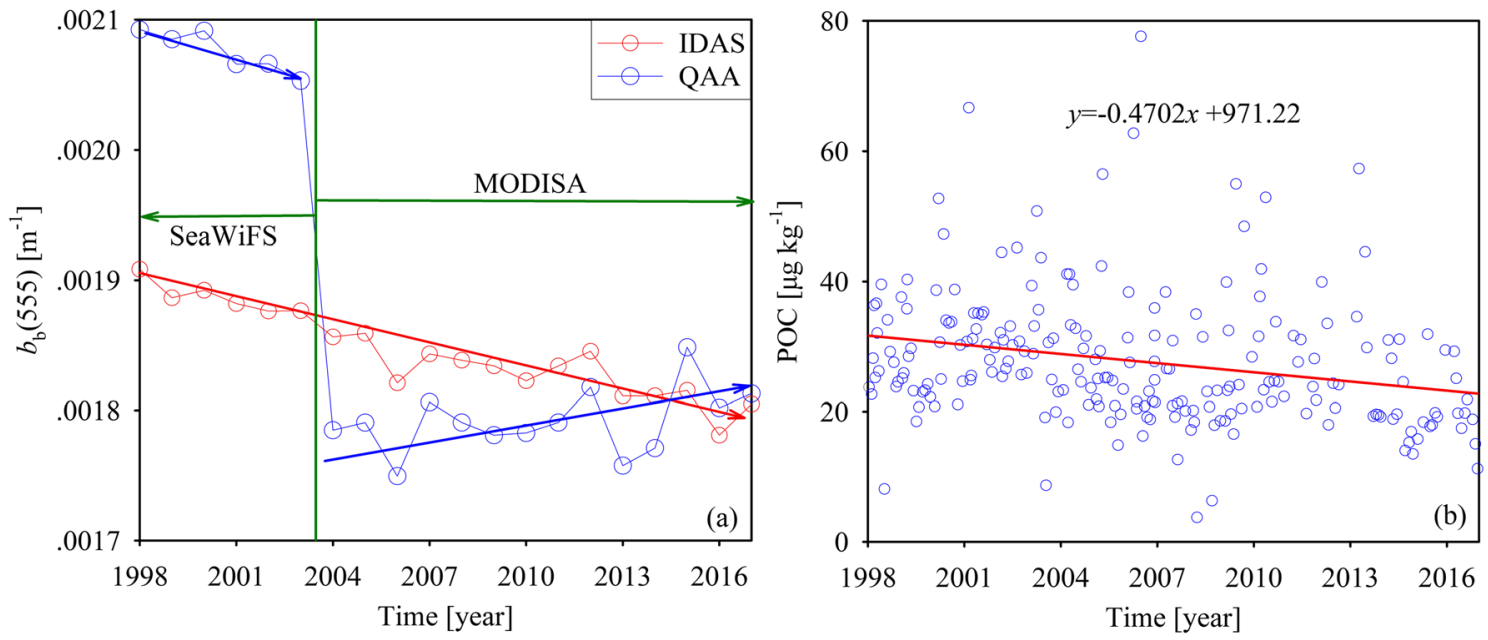

Figure 16. Changing trend of (a) $b_{\mathrm{b}}(555)$ and (b) POC in the Northwest Atlantic Subtropical Ocean $\left(20^{\circ}\right.$ to $30^{\circ} \mathrm{N}, 50^{\circ}$ to $\left.60^{\circ} \mathrm{W}\right)$ from 1998 to 2017 . The yearly $b_{\mathrm{b}}(555)$ changing pattern in the North Atlantic Gyre before and after 2003 are, respectively, retrieved from SeaWiFS and MODISA Level-2 data. All "high-quality" pixels with $R_{\mathrm{rs}}(\lambda)>0$ were included in the analysis. The "circle" in (a) represents the yearly mean $b_{\mathrm{b}}(555)$ calculated from all pixels in daily images within the $10^{\circ} \times$ $10^{\circ}$ square region, while the "circle" in (b) represents the field-measured POC concentration. The "red line" in (b) represents the linear relationship between POC concentration and time.

\section{2. $b_{\mathrm{b}}(555)$ Trend Analysis in the Oligotrophic Northwest Atlantic Subtropical Ocean}

Mélin (2016) indicated that the satellite-derived climate record of oligotrophic oceans is more sensitive to intermission differences than other kinds of satellite records in trend analysis. We computed the trend in $b_{\mathrm{b}}(555)$ in the Northwest Atlantic Subtropical Ocean $\left(20^{\circ}\right.$ to $30^{\circ} \mathrm{N}, 50^{\circ}$ to $\left.60^{\circ} \mathrm{W}\right)$, before and after 2003 , from the HQ SeaWiFS (1998 to 2003) and MODISA (2004 to 2017) Level-2 data, respectively, as shown in Figure 16a. The factors affecting the intermission difference between sensors with a large-analysis window were much more complicated than with a small-analysis window. For example, in addition to differences originating from the sensor's spectral characteristics, instrument noise, data processing procedures, and so on, the intermission differences were also impacted by the instantaneous variations in foams, Sun glints, atmospheric composition, coverage, and so on. We do not discuss the consistency of $b_{\mathrm{b}}(555)$ for years common to both sensors in the large-analysis window.

Due to the sensitivity of QAA to intermission differences in $R_{\mathrm{rs}}$, we found a significant discontinuity from the QAA $b_{\mathrm{b}}(555)$ interannual trend at the intermediate node where SeaWiFS switched to MODISA. After processing with IDAS, this discontinuity significantly improved, and the time series became smoother. Moreover, Figure 16a shows that the overall IDAS $b_{\mathrm{b}}(555)$ interannual trend differed from the QAA results. Specifically, the yearly mean QAA $b_{\mathrm{b}}(555)$ clearly decreased from 1998 to 2003 but increased from 2004 to 2017. In contrast to the QAA results, the yearly mean IDAS $b_{\mathrm{b}}(555)$ monotonically decreased from 0.00191 to $0.00181 \mathrm{~m}^{-1}$ during the past two decades, with the decadal decreasing ratio reaching $2.81 \%$. The temporal change patterns of IDAS $b_{\mathrm{b}}(555)$ were similar to the QAA $b_{\mathrm{b}}(555)$ trend at interannual scales from 2004 to 2017. For example, the interannual change curves of QAA and IDAS $b_{\mathrm{b}}(555)$ had peaks and troughs during the same year. However, the interannual variation amplitudes for QAA $b_{\mathrm{b}}(555)$ were much larger than the IDAS $b_{\mathrm{b}}$ (555) variation amplitudes in 2003 due to the high intermission difference sensitivity of QAA, which resulted in the difference in the trends between the IDAS and QAA $b_{\mathrm{b}}(555)$ at decadal scales. Therefore, the residual error and intermission bias significantly improved and were meaningful for decadal $b_{\mathrm{b}}(555)$ trend analysis with IDAS in the Northwest Atlantic Subtropical Ocean.

The traditional bio-optical definition of Case I waters assumes that the optical properties of the open ocean mainly depend on chlorophyll-a concentration and its covarying matter (Morel \& Prieur, 1977). However, due to the impacts of atmospheric deposition of mineral dust transported from Africa (Sarthou et al., 2003), the ratio of particulate organic matter to suspended particulate matter in the North Atlantic Ocean is as low as $<50 \%$ (Stramski et al., 2008). Therefore, it is difficult to confirm the actual annual trend of $b_{\mathrm{b}}(555)$ in the North Atlantic Ocean using only chlorophyll-a even though Mélin (2016) showed from 
merged SeaWiFS and MODISA chlorophyll-a series that the chlorophyll-a concentration in this region changes significantly at $-1.84 \%$ per year. Stramski et al. $(2008,1999)$ found a high correlation between $b_{\mathrm{b}}(555)$ and POC $\left(R^{2}>0.87\right)$ in the North Atlantic, despite particulate organic matter contributing very little to the total suspended matter. In the end, we decided to use POC to assess the trend in $b_{\mathrm{b}}(555)$.

According to the Bermuda time series site for the northwestern part of the oligotrophic Northwest Atlantic, POC changed by $1.7 \%$ per year during the past two decades (Figure 16b). These results support the assumption that $b_{\mathrm{b}}(555)$ decreased in the Northwest Atlantic Subtropical Ocean over the past two decades, which is consistent with the results produced by IDAS.

\section{Conclusion}

The ocean color community uses continuous multimission ocean color data to study the impacts of global climate change on ocean ecology. Our main objective in this study was to demonstrate how well our IDAS algorithm performed in removing intermission differences in IOPs retrievals. Eliminating the differences among missions is important because IOPs are directly linked to biogeochemical properties including phytoplankton biomass, gelbstoff, and suspended particles. We presented a series of simple formulas that explain the physical mechanism of IDAS in correcting intermission biases. After applying the algorithm to field measurements and satellite images, we found that the intermission difference between SeaWiFS and MODISA $R_{\mathrm{rs}}$ data mainly originated from SeaWiFS residual errors. The IDAS algorithm removed the residual errors in satellite $R_{\mathrm{rs}}$, and simultaneously partially reduced the intermission bias. In this way, the IDAS algorithm provided accurate and temporally consistent IOPs products for the open ocean.

We used HQ SeaWiFS and MODISA Level- $2 R_{\mathrm{rs}}$ data to compare results we obtained with IDAS to results we obtained with another algorithm called QAA. IDAS provided intermission consistency for the IOPs products with less than 3\% intermission differences for the oligotrophic open ocean, which was much lower than what we obtained using the QAA algorithm.

Furthermore, we used IDAS to understand the temporal trend of $b_{\mathrm{b}}(555)$ in the Northwest Atlantic Ocean from 1998 to 2017 . The results showed that the yearly mean IDAS $b_{\mathrm{b}}(555)$ monotonically decreased by $2.81 \%$ per decade, which was consistent with the change of POC in the Bermuda Sea and chlorophyll-a concentration in the Northwest Atlantic Subtropical Ocean. Comparing the trend results that we obtained with IDAS to trend results obtained with QAA, we found slightly different temporal patterns in $b_{\mathrm{b}}(555)$ for the same decades. We concluded that the difference in resulting trends between the two algorithms was because of differing resulting residual errors and intermission biases. The QAA results reminded us that residual error and intermission bias could result in misleading conclusions from trend analysis. Although we need further tests to validate the corrected data products, these preliminary results indicated that the IDAS algorithm has the potential to minimize effects of intermission differences in long-term monitoring with satellites. Even though we only applied our system to NASA missions, after some adjustments it should also be applicable to ocean color missions carried out by the European Space Agency, the National Oceanic and Atmospheric Administration, and the Chinese National Satellite Ocean Application Service.

\section{Appendix A.: Brief Overview of Mathematical Relationships in IDAS}

Because satellite observe $R_{\mathrm{rs}}$ just above the sea surface, $R_{\mathrm{rs}}$ should be converted into $r_{\mathrm{rs}}$ just below the sea surface for IOPs retrievals (Mobley, 1994):

$$
r_{r s}(\lambda)=\frac{R_{r S}(\lambda)}{0.52+1.7 R_{r s}(\lambda)}
$$

According to Gordon et al. (1988) and Lee et al. (2009), $r_{\mathrm{rs}}$ is a function of IOPs as follows:

$$
r_{r s}(\lambda)=0.089 \frac{b_{b}(\lambda)}{a(\lambda)+b_{b}(\lambda)}+0.1245\left[\frac{b_{b}(\lambda)}{a(\lambda)+b_{b}(\lambda)}\right]^{2}
$$

where $a$ is the total absorption coefficient, and $b_{\mathrm{b}}$ is the total backscattering coefficient. 

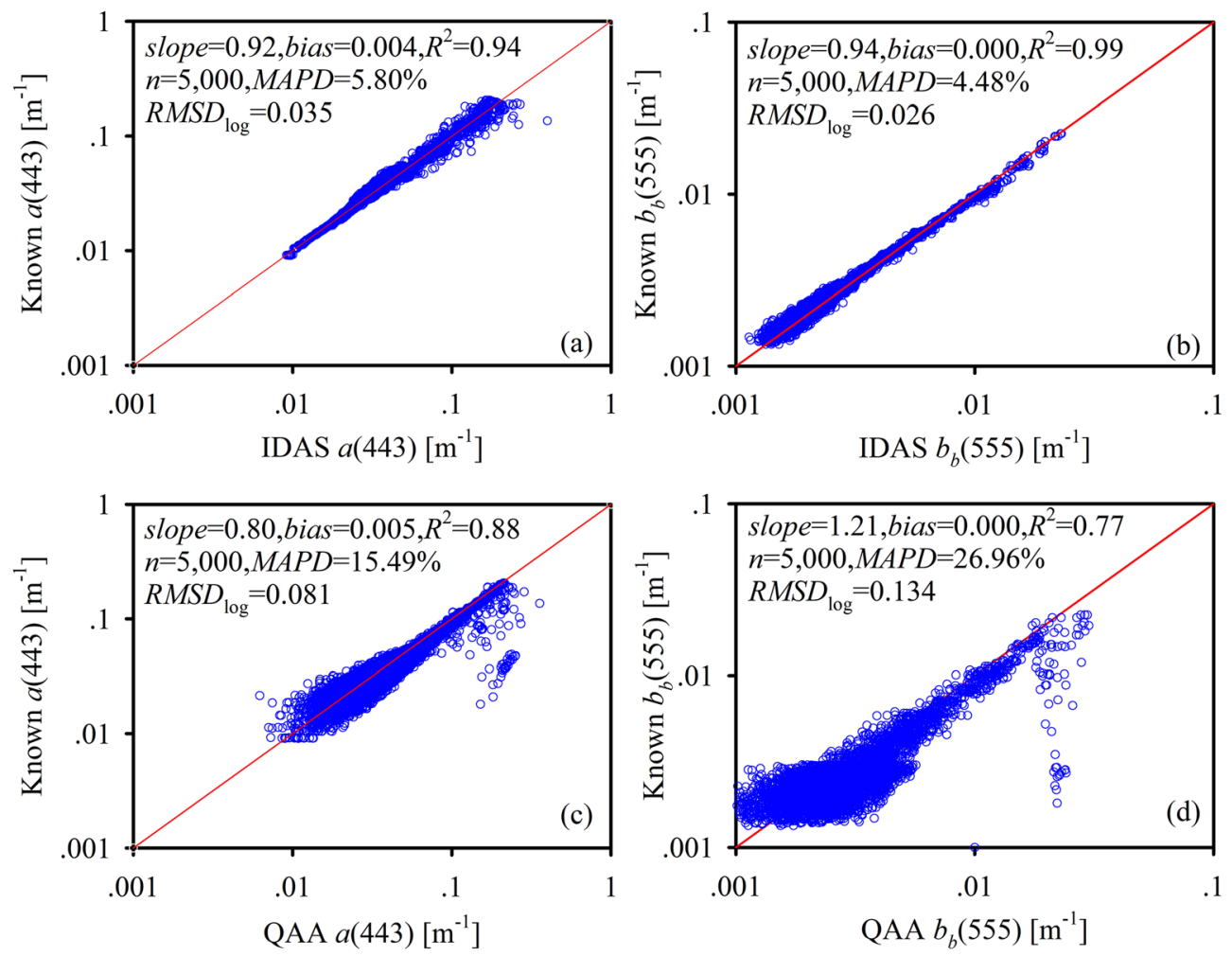

Figure B1. Same as Figure 9 but for SeaWiFS and MODISA Level-2 data over a small region within the South Pacific Gyre ( $34^{\circ}$ to $36^{\circ} \mathrm{S}, 114^{\circ}$ to $\left.116^{\circ} \mathrm{W}\right)$ from 2009 . (a)-(c) are original $R_{\mathrm{rs}}$, while (d)-(f) are IDAS $R_{\mathrm{rs}}$; (g) and (h) are QAA and IDAS daily mean $b_{\mathrm{b}}(555)$. The "red line" represents the results from SeaWiFS images $(n$ $\left.=1.9 \times 10^{6}\right)$, while the "blue bar" or "blue line" represents the results from MODISA images $\left(n=7.7 \times 10^{6}\right)$. The "circle" represents the daily mean $b_{\mathrm{b}}(555)$ within a $2^{\circ} \times 2^{\circ}$ square region, while the "vertical bar" denotes as the mean deviation within the $2^{\circ} \times 2^{\circ}$ square region. The histograms were calculated from all pixels in the $2^{\circ}$ $\times 2^{\circ}$ square region in original or IDAS-corrected daily images from 2009 .

Based on the assumption of a spectral linear relationship for $\triangle R_{\mathrm{rs}, \mathrm{r}}$, Chen et al. (2016) developed an algorithm for REC as follows:

$$
\begin{gathered}
0.089 \frac{b_{b}(555)}{a(555)+b_{b}(555)}+0.1245\left[\frac{b_{b}(555)}{a(555)+b_{b}(555)}\right]^{2}= \\
\frac{R_{r s, s}(555)-S(555,670) \Delta R_{r s, r}(670)+B(555,670)}{0.52+1.7\left[R_{r s, s}(555)-S(555,670) \Delta R_{r s, r}(670)+B(555,670)\right]} \\
0.089 \frac{b_{b}(670)}{a(670)+b_{b}(670)}+0.1245\left[\frac{b_{b}(670)}{a(670)+b_{b}(670)}\right]^{2}= \\
\frac{R_{r s, s}(670)-\Delta R_{r s, r}(670)}{0.52+1.7\left[R_{r s, s}(670)-\Delta R_{r s, r}(670)\right]}
\end{gathered}
$$

where $R_{\mathrm{rs}, \mathrm{s}}$ represents the satellite-derived $R_{\mathrm{rs}}$ and $a_{\mathrm{w}}$ refers to the absorption coefficient of pure water. Note that the $a_{\mathrm{w}}$ is much larger than the absorption coefficient of particle and gelbstoff at $670 \mathrm{~nm}$ in the open ocean; thus, $a(670)$ can be approximated by the $a_{\mathrm{w}}(670)$ in equation (A4). In equations (A3) and (A4), the left-hand terms denote the $R_{\mathrm{rs}}$ based on IOP- $R_{\mathrm{rs}}$ relationships, while the right-hand terms represent the theoretical error-free $R_{\mathrm{rs}} \cdot b_{\mathrm{b}}(670)$ has strong spectral dependence and is denoted as follows:

$$
b_{b}(670)=\left(\frac{555}{670}\right)^{Y}\left[b_{b}(555)-b_{b w}(555)\right]+b_{b w}(670)
$$

where $b_{\mathrm{bw}}$ represents the backscattering coefficient of pure seawater.

Because $S(555,670)$ and $B(555,670)$ can be fixed using the approach that $\mathrm{Hu}$ et al. (2013) proposed, equations (A3) and (A4) still contain four unknowns: $a(555), b_{\mathrm{b}}(555), Y$, and $\triangle R_{\mathrm{rs}, \mathrm{r}}(670)$, after 

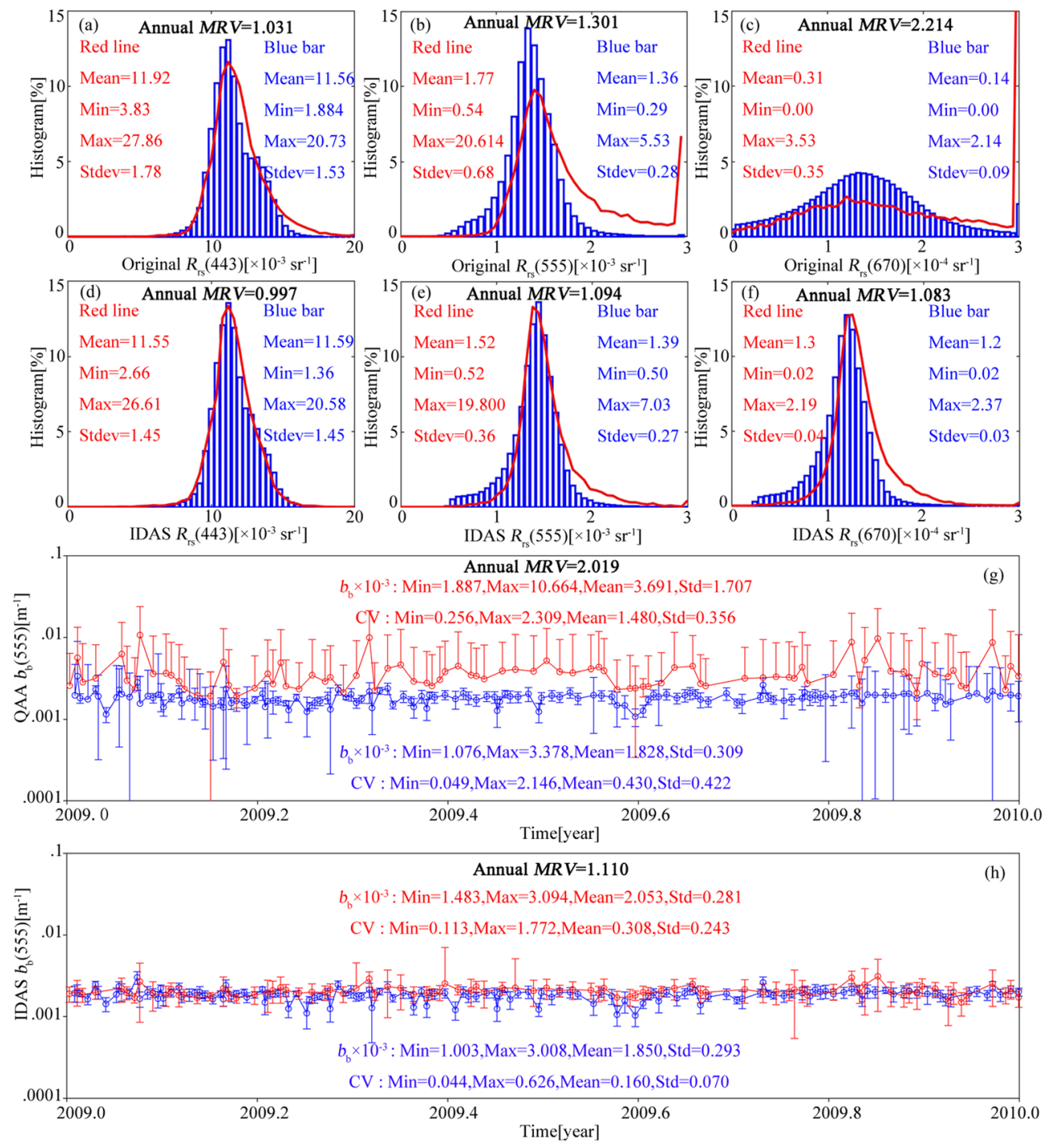

Figure B2. Same as Figure 10 but for SeaWiFS and MODISA Level-2 data over a small region within the South Pacific Gyre $\left(34^{\circ}\right.$ to $36^{\circ} \mathrm{S}, 114^{\circ}$ to $\left.116^{\circ} \mathrm{W}\right)$ from 2009 . (a)-(c) are original LQ $R_{\mathrm{rs}}$, while (e)-(g) are original HQ $R_{\mathrm{rs}}$; (d) and (h) are QAA $b_{\mathrm{b}}(555)$ derived from original LQ and HQ $R_{\mathrm{rs}}$ data; (i)-(k) are IDAS-corrected LQ $R_{\mathrm{rs}}$, while (m)-(o) are IDAS-

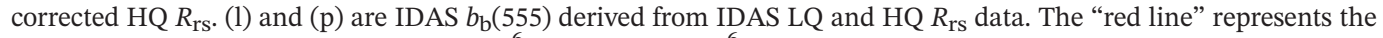
results from SeaWiFS images $\left(n=0.8 \times 10^{6}\right.$ and $n=1.1 \times 10^{6}$, respectively, for HQ and LQ data), while the "blue bar" represents the results from MODISA images $\left(n=3.2 \times 10^{6}\right.$ and $n=4.5 \times 10^{6}$, respectively, for HQ and LQ data). All pixels with $R_{\mathrm{rs}}(\lambda)>0$ were analyzed. The histograms were calculated from all pixels in the $2^{\circ} \times 2^{\circ}$ square region in original or IDAS-corrected daily images from 2009. The 12_flags distinguished HQ pixels from LQ pixels.

substituting equation (A5) into equation (A4). To solve $\triangle R_{\mathrm{rs}, \mathrm{r}}$ from equations (A3) and (A4) algebraically for each $R_{\mathrm{rs}, \mathrm{s}}$ spectrum, two unknowns still need to be fixed. Many algorithms have been developed for determining $a(555)$ and $Y$ from $R_{\mathrm{rs}}$ data (Chen et al., 2014; IOCCG, 2006; Lee et al., 2002; Werdell et al., 2013), but most of the algorithms were based on the band ratio approach. Band ratio approaches are very sensitive to the residual errors in satellite $R_{\mathrm{rs}}$ data (Chen et al., 2016; Hu et al., 2013). To overcome this sensitivity problem, Chen et al. (2016) developed a band difference approach neural network algorithm for retrieving $a(555)$ and $Y$ from $R_{\mathrm{rs}}$ data. Moreover, the neural network algorithm was trained by including residual errors in error-free $R_{\mathrm{rs}}$ data, so that it could diminish some influences from the residual errors and obtain better results than the band ratio approaches obtained (Chen et al., 2016). When $a(555)$ and $Y$ are derived with the neural network algorithm, $\triangle R_{\mathrm{rs}, \mathrm{r}}$ and $b_{\mathrm{b}}(555)$ can be determined algebraically for each satellite $R_{\mathrm{rs}}$ spectrum. 


\section{Appendix B.: Assessing Algorithms With Satellite Images of the South Pacific Gyre}

We used SeaWiFS and MODISA Level-2 data (HQ and LQ data) obtained for the South Pacific Gyre from 2009 to further demonstrate the capability of IDAS in generating intermission consistent $b_{\mathrm{b}}(555)$ for global blue water. Similar to the results obtained from LQ and HQ $R_{\mathrm{rs}}$ data for the North Atlantic Gyre from 2009, the annual MRV values for the original $R_{\mathrm{rs}}$ data were 1.031, 1.301, and 2.214, respectively, at 443, 555, and $670 \mathrm{~nm}$ (Figures B1a to B1c), but the corresponding MRV values decreased significantly to 0.997, 1.093, and 1.083, respectively, after correcting with IDAS (Figures B1d to B1f).

As expected, due to the low noise tolerance of the QAA algorithm to residual errors and intermission bias, the QAA $b_{\mathrm{b}}(555)$ derived from SeaWiFS data was about onefold larger than the QAA $b_{\mathrm{b}}(555)$ derived from the MODISA data (Figure B1g). After processing with IDAS, the SeaWiFS $b_{\mathrm{b}}(555)$ time series varied at almost the same level as the MODISA $b_{\mathrm{b}}(555)$ time series, and the annual MRV value for $b_{\mathrm{b}}(555)$ decreased from 2.019 to 1.110 (Figure B1h).

We divided the SeaWiFS and MODISA Level- $2 R_{\mathrm{rs}}$ data into LQ and HQ $R_{\mathrm{rs}}$ data by turning the 12_flags on and off. Then we used the IDAS and QAA algorithms to retrieve the IOPs from these data (Figure B2). The results show that the QAA algorithm with $\mathrm{HQ} R_{\mathrm{rs}}$ data performed well in generating the intermission consistent $b_{\mathrm{b}}(555)$ products (Figure B2d), but the annual MRV value still reached 1.127, which exceeded the $\pm 3 \%$ maximum interannual variability of $b_{\mathrm{b}}(555)$ for blue water. Despite the fact that some unsystematic differences were found in the LQ and HQ $R_{\mathrm{rs}}$ data (Figures B2a to B2h), IDAS still generated good intermission consistent $b_{\mathrm{b}}(555)$ data from the LQ and HQ $R_{\mathrm{rs}}$ data (Figures B2i-B2p). The annual MRV values for $b_{\mathrm{b}}(555)$ were 1.176 and 1.022, respectively, for the LQ and HQ $R_{\mathrm{rs}}$ data processed with IDAS. The former was comparable to the QAA results derived from the HQ $R_{\mathrm{rs}}$ data, and the latter was like the intermission difference level for the North Atlantic Gyre data from 2009. Therefore, we concluded that IDAS is an effective approach for achieving consistent $b_{\mathrm{b}}(555)$ data from multiple missions for the open ocean.

\section{Acknowledgments}

Financial support for this study was provided by the National Key R\&D Program of China 2018YFB0504800 (2018YFB0504802, Chen), the National Natural Science Foundation of China (41876032, Xing, 41730536, Xing, and 41676171, Xing), Shanxi Key Research and Development Program (2018ZDXM-GY-023, Chen), and Fundamental Research Funds for the Central Universities (60020302, Chen). We would also like to thank NASA for providing the ocean color data and thank the two anonymous reviewers for their valuable comments. The data are available at the website (https://oceandata.sci.gsfc.nasa.gov/ and https://seabass.gsfc.nasa.gov).

\section{References}

Ahmad, Z., Franz, B., McClain, C., Kwiatkowska, E., Werdell, J., Shettle, E., \& Holben, B. (2010). New aerosol models for the retrieval of aerosol optical thickness and normalized water-leaving radiances from the SeaWiFS and MODIS sensors over coastal regions and open oceans. Applied Optics, 49(29), 5545-5560. https://doi.org/10.1364/AO.49.005545

Aiken, J., Moore, G. F., Trees, C. C., Hook, S. B., \& Clark, D. K. (1995). The SeaWiFS CZCS-type pigment algorithm, SeaWiFS Technical Report Series, Goddard Space Flight Center, Greenbelt, MD., 29.

Bailey, S. W., \& Werdell, P. J. (2006). A multi-sensor approach for the on-orbit validation of ocean color satellite data products. Remote Sensing of Environment, 102, 12-23.

Ballabrera-Poy, J., Murtugudde, R. G., Christian, J. R., \& Busalacchi, A. J. (2003). Signal-to-noise ratios of observed monthly tropical ocean color. Geophysical Research Letter, 30(12), 1645. https://doi.org/10.1029/2003GL016995

Ballabrera-Poy, J., Murtugudde, R. G., Zhang, R.-H., \& Busalacchi, A. J. (2007). Coupled ocean-atmosphere response to seasonal modulation of ocean color: Impact on interannual climate simulations in the tropical Pacific. Journal of Climate, 20, 353-374.

Behrenfeld, M. J., Westberry, T. K., Boss, E. S., O\&amp;apos;Malley, R. T., Siegel, D. A., Wiggert, J. D., et al. (2009). Satellite-detected fluorescence reveals global physiology of ocean phytoplankton. Biogeosciences, 6(5), 779-794. https://doi.org/10.5194/bg-6-779-2009

Bojinski, S., Verstraete, M., Peterson, T. C., Richter, C., Simmons, A., \& Zemp, M. (2014). The concept of essential climate variables in support of climate research, applications, and policy. Bulletin of the American Meteorological Society, 95, 1431-1443.

Boyce, D. G., Lewis, M. R., \& Worm, B. (2010). Global phytoplankton decline over the past century. Nature, 466(7306), 591-596. https://doi. org/10.1038/nature09268

Carder, K. L., Chen, F. R., Cannizzaro, J. P., Campbell, J. W., \& Mitchell, B. G. (2004). Performance of the MODIS semi-analytical ocean color algorithm for chlorophyll-a. Advances in Space Research, 33, 1152-1159.

CCI (2016). Ocean color data bias correction and merging, Ocean Colour-Climate Change Initiative, Algorithm Theoretical Bias Document, Version 2.0.

Chen, J., Lee, Z. P., Hu, C. M., \& Wei, J. W. (2016). Improving satellite data products for open oceans with a scheme to correct the residual errors in remote sensing reflectance. Journal of Geophysical Research: Ocean, 121, 3866-3886. https://doi.org/10.1002/2016JC011673

Chen, J., Quan, W. T., Cui, T. W., Song, Q. J., \& Lin, C. S. (2014). Remote sensing of absorption and scattering coefficient using neural network model: Development, validation, and application. Remote Sensing of Environment, 149, 213-226.

Cotroneo, Y., Aulicino, G., Ruiz, S., Pascual, A., Budillon, G., Fusco, G., \& Tintoré, J. (2016). Glider and satellite high resolution monitoring of a mesoscale eddy in the algerian basin: effects on the mixed layer depth and biochemistry. Journal of Marine Systems, 162(Supplement C), 73-88. https://doi.org/10.1016/j.jmarsys.2015.12.004

Eplee, R. E., Sun, J. Q., Meister, G., Patt, F. S., Xiong, X., \& McClain, C. R. (2011). Cross calibration of SeaWiFS and MODIS using on-orbit observations of the Moon. Applied Optics, 50(2), 120-133.

Ford, D., \& Barciela, R. (2017). Global marine biogeochemical reanalyses assimilating two different sets of merged ocean colour products. Remote Sensing of Environment, 203, 40-54. https://doi.org/10.1016/j.rse.2017.03.040

Gao, Z. G., Duan, H. T., Shen, M., Ma, R. H., Xue, K., Liu, D., \& Xiao, Q. T. (2018). Using VIIRS/NPP and MODIS/Aqua data to provide a continuous record of suspended particulate matter in a highly turbid inland lake. International Journal of Applied Earth Observation and Geoinformation, 64, 256-265. 
Garver, S. A., \& Siegel, D. A. (1997). Inherent optical property inversion of ocean color spectral and its biogeochemical interpretation. 1. Time series from the Sargasso Sea. Journal of Geophysical Research, 102, 18607-18625.

Gordon, H. R. (1998). In-orbit calibration strategy for ocean color sensors. Remote Sensing of Environment, 63(3), 265-278.

Gordon, H. R., Brown, O. B., Evans, R. H., Brown, J. W., Smith, R. C., \& Baker, K. S. (1988). A semianalytic radiance model of ocean color. Journal of Geophysical Research, 93, 10,909-10,924.

Gordon, H. R., Clark, D. K., Mueller, J. L., \& Hovis, W. A. (1980). Phytoplankton pigments derived from the Nimbus-7 CZCS: Initial comparisons with surface measurements. Science, 210(4465), 63-66. https://doi.org/10.1126/science.210.4465.63

Gordon, H. R., \& Voss, K. J. (1999). MODIS normalized water-leaving radiance algorithm theoretical basis document (MOD 18) Version 4, Unpublished Report. https://modis.gsfc.nasa.gov/data/atbd/atbd_mod17.pdf

Gordon, H. R., \& Wang, M. (1994). Retrieval of water-leaving radiance and aerosol optical thickness over the oceans with SeaWiFS: A preliminary algorithm. Applied Optics, 33(3), 443-452. https://doi.org/10.1364/AO.33.000443

Gregg, W. W., \& Casey, N. W. (2010). Improving the consistency of ocean color data: A step toward climate data records. Geophysical Research Letters, 37, L04605. https://doi.org/10.1029/2009GL041893

Gregg, W. W., Casey, N. W., O'Reilly, J. E., \& Esaias, W. E. (2009). An empirical approach to ocean color data: Reducing bias and the need for post-launch radiometric re-calibration. Remote Sensing of Environment, 113(8), 1598-1612.

Gregg, W. W., \& Conkright, M. E. (2001). Global seasonal climatologies of ocean cholophyll: blendding in situ and satellite data for the coastal zone color scanner era. Journal of Geophysical Research, 106, 2499-2515.

Gundersen, K., Orcutt, K. M., Purdie, D. A., Michaels, A. F., \& Knap, A. H. (2001). Particulate organic carbon mass distribution at the Bermuda Atlantic Time-series Study (BATS) site. Deep Sea Research Part II: Topical Studies in Oceanography, 48(8), 1697-1718. https:// doi.org/10.1016/S0967-0645(00)00156-9

Hooker, S. B. (2003). Algorithm updates for the Fourth SeaWiFS Data Reprocessing, NASA Technical Memorandum 2003-206892.

Hooker, S. B., Zibordi, G., Berthon, J.-F., D'Alimonte, D., Maritorena, S., McLean, S., \& Sildam, J. (2001). Results of the second SeaWiFS data analysis round robin (p. 71). Greenbelt, MD: NASA Goddard Space Flight Center.

Hu, C. M. (2011). An empirical approach to derive MODIS ocean color patterns under severe sun glint. Geophysical Research Letters, 38, L01603. https://doi.org/10.1029/2010GL045422

Hu, C. M., Feng, L., \& Lee, Z. P. (2013). Uncertainties of SeaWiFS and MODIS remoe sensing reflectance: Implications from clear water measurements. Remote Sensing of Environment, 133, 168-182.

Ibrahim, A., Franz, B., Ahmad, Z., Healy, R., Knobelspiesse, K., Gao, B. C., et al. (2018). Atmospheric correction for hyperspectral ocean color retrieval with applications to the Hyperspectral Image for the Coastal Ocean (HICO). Remote Sensing of Environment, 204, 60-75.

Ioannou, I., Gilerson, A., Gross, B., Moshary, F., \& Ahmed, S. (2013). Deriving ocean color products using neural networks. Remote Sensing of Environment, 134, 78-91. https://doi.org/10.1016/j.rse.2013.02.015

IOCCG (2006). Remote sensing of inherent optical properties: Fundamentals, tests of algorithms, and applications, Reports of the International Ocean Colour Coordinating Group No.5, IOCCG, Dartmouth, Canada.

IOCCG (2007). Ocean-Colour Data Merging, in Reports of the International Ocean-Colour Coordinating Group, No. 6, edited by W. Gregg, p. 68, International Ocean-Colour Coordinating Group, Dartmouth, Canada.

Jamet, C., Loisel, H., \& Dessailly, D. (2012). Retrieval of the spectral diffuse attenuation coefficient K-d (lambda) in open and coastal ocean waters using a neural network inversion. Journal of Geophysical Research, 117, C10023. https://doi.org/10.1029/2012jc008076

Kahru, M., Lee, Z., Kudela, R. M., Manzano-Sarabia, M., \& Mitchell, B. G. (2015). Multi-satellite time series of inherent optical properties in the California Current. Deep Sea Research Part II: Topical Studies in Oceanography, 112(Supplement C), 91-106. https://doi.org/10.1016/ j.dsr2.2013.07.023

Kwiatkowska, E. J., \& Fargion, G. S. (2003). Application of machine-learning techniques towards the creation of a consistent and calibrated global chlorophyll concentration baseline dataset using remotely sensed ocean color data. IEEE Transactions on Geoscience and Remote Sensing, 41(12), 2844-2860.

Lee, Z. P., Carder, K. L., \& Arnone, R. A. (2002). Deriving inherent optical properties from water color: A multi-band quasi-analytical algorithm for optically deep waters. Applied Optics, 41(27), 5755-5772. https://doi.org/10.1364/ao.41.005755

Lee, Z.-P., Hu, C., Casey, B., Shang, S. L., Dierssen, H., \& Arnone, R. (2010). Global shallow-water bathymetry from satellite ocean color data. EOS Transactions, 91(46), 429-430.

Lee, Z. P., Lubac, B., Werdell, P. J., \& Arnone, R. (2009). An update of the quasi-analytical algorithm (QAA_v5), IOCCG software report (www.iocg.org/groups/software_OCA), http://www.ioccg.org/groups/Software_OCA/QAA_v5.pdf

Lee, Z.-P., Pahlevan, N., Ahn, Y.-H., Greb, S., \& O'Donnell, D. (2013). A robust approach to directly measure water-leaving radiance in the field. Applied Optics, 52(8), 1693-1701. https://doi.org/10.1364/AO.52.001693

Lewis, M. R., Carr, M. E., Feldman, G. C., Esias, W., \& McClain, C. (1990). Influence of penetrating solar radiation on the heat budget of the Equatorial Pacific. Nature, 347, 543-546.

Mahadevan, A., D'Asaro, E., Lee, C., \& Perry, M. J. (2012). Eddy-driven stratification initiates North Atlantic spring phytoplankton blooms. Science, 337(6090), 54-58. https://doi.org/10.1126/science.1218740

Maritorena, S., \& Siegel, D. A. (2005). Consistent merging of satellite ocean color data sets using a bio-optical model. Remote Sensing of Environment, 94, 429-440.

Mélin, F. (2016). Impact of inter-mission differences and drifts on chlorophyll-a trend estimates. International Journal of Remote Sensing, 37, 2061-2079.

Mélin, F., Sclep, G., Jackson, T., \& Sathyendranath, S. (2016). Uncertainty estimates of remote sensing reflectance derived from comparison of ocean color satellite data sets. Remote Sensing of Environment, 177, 107-124. https://doi.org/10.1016/j.rse.2016.02.014

Mélin, F., Vantrepotte, V., Chuprin, A., Grant, M., Jackson, T., \& Sathyendranath, S. (2017). Assessing the fitness-for-purpose of satellite multi-mission ocean color climate data records: A protocol applied to OC-CCI chlorophyll-a data. Remote Sensing of Environment, 203, 139-151. https://doi.org/10.1016/j.rse.2017.03.039

Mobley, C. D. (1994). Light and Water: radiative transfer in natural waters (p. 592). New York: Academic Press.

Mobley, C. D., \& Sundman, L. K. (2013). HydroLight 5.2 User's Guide, Sequoia Scientific, Inc., Bellevue, Washington.

Morel, A., \& Prieur, L. (1977). Analysis of variances in ocean color. Limnology and Oceanography, 22, 709-722.

Mueller, J. L., Fargion, G. S., \& McClain, C. R. (2003). Ocean optics protocols for satellite ocean color sensor validation, Revision 4, NASA, Goddard Space Flight Center, Greenbelt, MD.

Pottier, C., Garcon, V., \& Larnico, G. (2006). Merging SeaWiFS and MODIS/Aqua ocean color data in North and Equatorial Atlantic using weighted averaging and objective analysis. IEEE Transactions on Geoscience and Remote Sensing, 44(11), 3436-3450. 
Quan, W. T. (2014). Vicarious cross-calibration of the China environment satellite using nearly simultaneously observations of Landsat-7 ETM sensor. Journal of the Indian Society of Remote Sensing, 42, 539-548.

Roy, S., Sathyendranath, S., \& Platt, T. (2017). Size-partitioned phytoplankton carbon and carbon-to-chlorophyll ratio from ocean colour by an absorption-based bio-optical algorithm. Remote Sensing of Environment, 194(Supplement C), 177-189. https://doi.org/10.1016/j. rse.2017.02.015

Sarthou, G., Baker, A. R., Blain, S., Achterberg, E. P., Boye, M., Bowie, A. R., et al. (2003). Atmospheric iron deposition and sea-surface dissolved iron concentrations in the eastern atlantic ocean. Deep Sea Research I, 50(10-11), 1339-1352. https://doi.org/10.1016/S09670637(03)00126-2

Saulquin, B., Fablet, R., Mangin, A., Mercier, G., Antoine, D., \& Fanton, D. O. (2013). Detection of linear trends in multisensor time series in the presence of autocorrelated noise: application to the chlorophyll-a SeaWiFS and MERIS data sets and extrapolation to the incoming Sentinel 3-OLCI mission. Journal of Geophysical Rsearch: Ocean, 118, 3752-3763. https://doi.org/10.1002/jgrc.20264

Siegel, D. A., Doney, S. C., \& Yoder, J. A. (2002). The North Atlantic spring phytoplankton bloom and Sverdrup's critical depth hypothesis. Science, 296, 730-732.

Son, S., \& Wang, M. (2015). Diffuse attenuation coefficient of the photosynthetically available radiation Kd (PAR) for global open ocean and coastal waters. Remote Sensing of Environment, 159, 250-258. https://doi.org/10.1016/j.rse.2014.12.011

Stramski, D., Reynolds, R. A., Babin, M., Kaczmarek, S., Lewis, M. R., Röttgers, R., et al. (2008). Relationships between the surface concentration of particulate organic carbon and optical properties in the eastern South Pacific and eastern Atlantic Oceans. Biogeosciences, 5(1), 171-201. https://doi.org/10.5194/bg-5-171-2008

Stramski, D., Reynolds, R. A., Kahru, M., \& Mitchell, B. G. (1999). Estimation of particulate organic carbon in the ocean from satellite remote sensing. Science, 285(5425), 239-242. https://doi.org/10.1126/science.285.5425.239

Strutton, P. G., \& Chavez, F. P. (2004). Biological heating in the equatorial Pacific: Observed variability and potential for real-time calculation. Journal of Climate, 17, 1097-1109.

Teillet, P. M., Fedosejevs, G., Thome, K. J., \& Barker, J. L. (2007). Impacts of spectral band difference effects on radiometric crosscalibration between satellite sensors in the solar-reflective spectral domain. Remote Sensing of Environment, 110, 393-409.

Tin, H. C., Lomas, M. W., \& Ishizaka, J. (2016). Satellite-derived estimates of primary production during the Sargasso Sea winter/spring bloom: Integration of in-situ time-series data and ocean color remote sensing observations. Regional Studies in Marine Science, 3(Supplement C), 131-143. https://doi.org/10.1016/j.rsma.2015.07.002

Wang, M. (2014). Chapter 4.2-Simulation of satellite visible, near-infrared, and shortwave-infrared measurements. In C. J. D. G. Zibordi \& C. P. Albert (Eds.), Experimental Methods in the Physical Sciences (pp. 451-488). USA: Academic Press. https://doi.org/10.1016/B978-012-417011-7.00014-3

Wang, M., \& Son, S. (2016). VIIRS-derived chlorophyll-a using the ocean color index method. Remote Sensing of Environment, 182, $141-149$. https://doi.org/10.1016/j.rse.2016.05.001

Werdell, P. J., \& Bailey, S. W. (2002). The SeaWiFS bio-optical archive and storage system (SeaBASS): Current architecture and implementation, Goddard Space Flight Center, Greenbelt, Maryland 20771.

Werdell, P. J., Franz, B. A., Bailey, S. W., Feldman, G. C., Boss, E., Brando, V. E., et al. (2013). Generalized ocean color inversion model for retrieving marine inherent optical properties. Applied Optics, 52(10), 2019-2037. https://doi.org/10.1364/AO.52.002019

Yuan, B. X., Sun, M., Xiong, L., Luo, Q. Z., Pradhan, S. P., \& Li, H. Z. (2019). Investigation of 3D deformation of transparent soil around a laterally loaded pile based on a hydraulic gradient model test. Journal of Building Engineering, 28, 1-9.

Zhang, C., Hu, C., Shang, S., Müller-Karger, F. E., Li, Y., \& Dai, M. (2006). Bridging between SeaWiFS and MODIS for continuity of chlorophyll-a concentration assessments off Southeastern China. Remote Sensing of Environment, 102, $250-263$.

Zhang, R. H. (2016). An ocean-biology-induced negative feedback on ENSO as derived from a hybrid coupled model of the Tropical Pacific. Journal of Geophysical Research: Ocean, 120, 8052-8076. https://doi.org/10.1002/2015JC011305

Zhang, R. H., Gao, C., Kang, X. B., Zhi, H., Wang, Z. G., \& Feng, L. C. (2015). ENSO modulations due to interannual variability of freshwater forcing and ocean biology-induced heating in the tropical Pacific. Scientific Reports, 5(1), 1-11. https://doi.org/10.1038/srep18506

Zibordi, G., Mélin, F., Voss, K. J., Johnson, B. C., Franz, B. A., Kwiatkowska, E., et al. (2015). System vicarious calibration for ocean color climate change applications: Requirements for in situ data. Remote Sensing of Environment, 159(Supplement C), 361-369. https://doi. org/10.1016/j.rse.2014.12.015 